\title{
CD73 Attenuates Alcohol-Induced Liver Injury and Inflammation via Blocking TLR4/MyD88/NF-kB Signaling Pathway
}

\author{
Zhen-Ni Liu ${ }^{1-3}$ \\ Xue $\mathrm{Wu}^{1-3}$ \\ Qian Fang ${ }^{1-3}$ \\ $\mathrm{Zi}$-Xuan $\mathrm{Li}^{\mathrm{I}-3}$ \\ Guo-Qing $\mathrm{Xia}^{\mathrm{I}-3}$ \\ Jun-Nan $\mathrm{Cai}^{\mathrm{I}-3}$ \\ Xiong-Wen Lv $\mathbb{D}^{1-3}$
}

'Inflammation and Immune Mediated Diseases Laboratory of Anhui Province, Anhui Institute of Innovative Drugs, School of Pharmacy, Anhui Medical University, Hefei, People's Republic of China; ${ }^{2}$ The Key Laboratory of AntiInflammatory and Immune Medicines, Ministry of Education, Hefei, People's Republic of China; ${ }^{3}$ Institute for Liver Diseases of Anhui Medical University, Hefei, People's Republic of China
Correspondence: Xiong-Wen Lv School of Pharmacy, Anhui Medical University, 8I Mei Shan Road, Hefei, Anhui Province, 230032, People's Republic of China

Email lyuxw@ahmu.edu.cn
Background: Alcoholic liver disease (ALD) is liver damage caused by long-term drinking. Inflammation plays a central role in the progression of ALD. CD73 is a ubiquitously expressed glycosylphosphatidylinositol-anchored glycoprotein that is a key enzyme that converts ATP into adenosine. Evidence has shown that CD73 plays an important role in many diseases, but the role and mechanism of CD73 in alcohol-induced liver injury and inflammation is still unclear.

Methods: The alcohol-induced liver injury and inflammation mouse model was established. The rAAV9-CD73 was used to overexpress CD73. Isolation of primary macrophages (MФ) from the liver was conducted. The effects of CD73 on alcohol-induced liver injury and inflammation were evaluated by quantitative real-time PCR, Western blotting, ELISA, and immunohistochemical assay. Flow cytometry was used to detect the cell cycle and apoptosis. Results: Our results showed that overexpression of CD73 can reduce alcohol-induced liver damage, lipid accumulation, and the secretion of inflammatory cytokines. pEX3-CD73 can promote RAW264.7 cells proliferation and inhibit apoptosis via suppressing the activation of TLR4/MyD88/NF- $\mathrm{BB}$ signaling pathway. Inhibition of TLR4 further enhanced the antiinflammatory effect of overexpression of CD73.

Conclusion: Overexpression of CD73 can reduce alcohol-induced liver injury and inflammation. CD73 may serve as a potential therapeutic target for ALD.

Keywords: CD73, alcohol-induced liver injury and inflammation, TLR4/MyD88/NF- $\mathrm{B}$ signaling pathway, apoptosis, RAW264.7 cells

\section{Introduction}

ALD is liver damage caused by long-term drinking, and is the leading cause of liver-related morbidity and mortality worldwide, characterized by liver inflammation. ${ }^{1}$ Every year, 3.3 million deaths occur because of alcohol. ${ }^{2}$ Studies have shown that alcoholic liver disease has become increasingly common in many parts of Asia, but it is declining in Western Europe. The situation of ALD in my country is not optimistic, and it should attract our attention., ${ }^{3,4}$ Despite the great harm of ALD, there are still no FDA-a pproved drugs or nutritional therapies to treat patients and only behavioral intervention and drug intervention are used for alcohol withdrawal treatment. ${ }^{5}$ The current academic view believes that liver damage, inflammation and liver fibrosis are important nodes in the progression of ALD. Inflammation plays a central role in the progression of ALD. ${ }^{6}$ 
Studies have shown that a large number of inflammatory cytokines released by macrophages are the key to liver injury, such as tumor necrosis factor-alpha (TNF- $\alpha$ ), interleukin-6 (IL-6), interleukin-10 (IL-10), and interleukin-1beta (IL-1 $\beta) .^{7-10}$ Notably, activation of HSCs is connected with several inflammatory cytokines, such as IL-6 and IL- $1 \beta .{ }^{11}$ It is particularly important to find an effective way to inhibit the expression of macrophages. Lipopolysaccharide (LPS) is the main component of the cell wall of gram-negative bacteria and the level of it is elevated in patients with alcoholic fatty liver or cirrhosis. ${ }^{12}$ Toll-like receptor 4 (TLR4) is a pattern recognition receptor that can recognize LPS. LPS then recruits the adaptor protein myeloid differentiation primary response gene 88 (MyD88) and activates the downstream proinflammatory transcription factor nuclear factor-kappa B (NF- $\mathrm{kB}$ ), a key regulator of the inflammatory response. ${ }^{13-16}$ Studies have shown that the TLR4 signaling pathway is activated by LPS in RAW264.7 cells and is associated with cell apoptosis. ${ }^{17}$ Our previous results of transcriptome sequencing in hepatic stellate cells (HSCs) (pEX3-NC vs pEX3CD73) showed that the Toll-like receptor signaling pathway and the NF- $\kappa B$ signaling pathway changed significantly when CD73 was overexpressed (data not shown). In summary, we speculate that CD73 may regulate the secretion of inflammatory cytokines and apoptosis of RAW264.7 cells through the TLR4/MyD88/NF- $\kappa B$ signaling pathway in alcohol-induced liver injury and inflammation.

CD73 is a ubiquitously expressed glycosylphosphatidylinositol-anchored glycoprotein that is a key enzyme that converts ATP into adenosine. Since CD73 is one of the critical components in the formation of an immunosuppressive microenvironment in cancers, it has become one of the hottest solid tumor targets on the market. Many articles have shown that CD73 is related to immunosuppression and tumor progression, and inhibition of CD73 expression can delay tumor growth and metastasis. ${ }^{18-21}$ CD73 plays a key role in the balance between inflammation and immune suppression. Studies have shown that CD73-mediated adenosine production leads to aggravation of hyperoxic lung injury and aggravates the inflammatory response. $^{22}$ Lacking CD73 can exacerbate allergic airway inflammation. ${ }^{23} \mathrm{CD} 73$ has been proven to play an important role in many diseases. ${ }^{19,24,25}$ In addition, our previous study found that inhibiting CD73 can promote the apoptosis of HSCs and reduce alcoholic liver fibrosis, but the role of CD73 in alcohol-induced liver injury and inflammation is unclear. In this study, we explored the role and mechanism of CD73 in alcohol-induced liver injury and inflammation. CD73, as an emerging potential target in clinical practice, is of great significance to explore its application in ALD.

\section{Materials and Methods}

Animal, Mouse Model of Alcohol-Induced Liver Injury and Inflammation

Male C57BL/6 mice (6-8 weeks) were obtained from Jinan Peng Yue Experimental Animal Breeding Co., Ltd. (Jinan, China). All experimental procedures in this study were approved by the Ethics Committee and Animal Experiment Committee of Anhui Medical University, which complies with the National Institute of Health Guide for the Care and Use of Laboratory Animals (NIH publication No. 85-23, revised 1985). First, the mice were fed in a comfortable environment for one week, and mice were randomly divided into four groups, namely, the control group, the EtOH-fed group, the rAAV9-empty-EtOH-fed group and the rAAV9-CD73-EtOHfed group. rAAV9 -CD73 and rAAV9-GFP-empty were injected via the tail vein three weeks later to start modeling. Except for the control group, mice were fed 5\% (vol/vol) alcoholic liquid feed for 16 days (including 2 days of liquid feed adaptation and 14 days of model building), the mice were given a single alcohol ( $5 \mathrm{~g} / \mathrm{kg}$ body weight) gavage on the last day, and the control group was given isocaloric maltosedextrin $(9 \mathrm{~g} / \mathrm{kg}$ body weight). After $9 \mathrm{~h}$ the mice were anesthetized. Liver tissues and blood were collected for the next experiment.

\section{In vivo Analysis of Bioluminescence}

Three weeks after rAAV9-GFP-empty injection, the mice were subjected to live imaging observation to determine whether the adeno-associated virus successfully infected the liver.

The mice were anesthetized and injected intraperitoneally with D-Luciferin potassium (Meilunbio, China). Ten minutes later, the mice were placed in the imaging chamber of the Xenogen in vivo imaging system. X-rays were used to further determine the specific location of the adeno-associated virus infection.

\section{Isolation of Liver Macrophages}

We used an in situ liver perfusion technique to extract liver macrophages. The liver was washed with perfusion buffer (including $\mathrm{NaCl}, \mathrm{KCl}, \mathrm{NaOH}$, and HEPES in $\mathrm{H}_{2} \mathrm{O}$ ) and then digested with digestion solution (collagenase IV, 
DNase and streptomycin) into a single cell suspension. Percoll (25\%) and Percoll (50\%) were used for density gradient centrifugation to separate liver macrophages. Finally, each group of isolated cells was added to protein cracking liquid to extract protein for the next experiment.

\section{Serum ALT, AST, T-CHO and TG Determination}

Aminotransferase (ALT), aspartate aminotransferase (AST), total cholesterol (T-CHO) and total triglyceride (TG) were detected by using assay kits. All kits were purchased from Nanjing Jiancheng Bioengineering Institute.

\section{Hematoxylin-Eosin (HE), Oil Red $\mathrm{O}$ and Bodipy Staining}

The livers of C57BL/6J mice were fixed in $4 \%$ paraformaldehyde for $48 \mathrm{~h}$. The fixed sections were $5 \mu \mathrm{m}$ thick and then stained with hematoxylin and eosin (H\&E), oil red $\mathrm{O}$ and BODIRY as described previously. ${ }^{26}$ Slides were scanned by an automatic digital slide scanner (Pannoramic MIDI, 3DHISTECH, Hungary).

\section{Immunohistochemical Staining}

The livers of C57BL/6J mice were fixed in $4 \%$ paraformaldehyde for $48 \mathrm{~h}$. Paraffin-embedded liver sections (5 $\mu \mathrm{m}$ thick) were deparaffinized and dehydrated, and antigen retrieval was obtained by microwave in citrate buffer for $15 \mathrm{~min}$. The sections were treated with $0.3 \%$ hydrogen peroxide for 15 min, blocked with $2 \%$ bovine serum albumin, and then blocked with anti-L-1 $\beta$ (1:500, Bioss, China), IL-6 (1:500, Bioss, China) and CD73 (1:500, Proteintech, USA) primary antibodies were incubated overnight. The next day, after incubation with biotinylated secondary antibody for $60 \mathrm{~min}$ at room temperature, staining was observed with 3,3-diaminobenzidine tetrahydrochloride (DAB) staining. The sections were counterstained with hematoxylin solution for $30 \mathrm{~s}$ and then dehydrated. Slides were scanned by an automatic digital slide scanner (Pannoramic MIDI, 3DHISTECH, Hungary).

\section{Immunofluorescence Staining}

Frozen liver tissue sections were permeabilized with $0.5 \%$ Triton X-100 in 1\% BSA for $10 \mathrm{~min}$. Then sections were blocked with 5\% BSA for $60 \mathrm{~min}$. At room temperature, antiCD73 (1:200; Abcam, USA) and anti-F4/80 (1:100; Santa Cruz, USA) were added to the slices. After $16 \mathrm{~h}$, the slices were incubated with a combination of TRITC-conjugated (1:100, ZSGB-Bio, China) and FITC-conjugated (1:100,
ZSGB-Bio, China) secondary antibodies under dark conditions for $60 \mathrm{~min}$. Finally, the slices were fixed with DAPI and the images were observed by inverted fluorescence microscope (OLYMPUS IX83, Tokyo, Japan).

\section{Cell Culture}

RAW264.7 cells were obtained from the Chinese Academy of Sciences (Shanghai, China). RAW264.7 cells were cultured in DMEM (HyClone, USA) supplemented with $10 \%$ fetal bovine serum (FBS, Biological Industries, Israel) and incubated at $37^{\circ} \mathrm{C}$ with $5 \% \mathrm{CO}_{2}$. RAW264.7 cells were treated with $100 \mathrm{mM} \mathrm{EtOH}$ for 24 $\mathrm{h}$ to establish the model. ${ }^{26}$

\section{Cell Proliferation Assay}

Approximately $2 \times 10^{4}$ transfected RAW264.7 cells were seeded in 96-well plates. After treatments, $10 \mu \mathrm{L}$ cell counting kit-8 (CCK8) (Best bio, China) reagent was added to each well and the cells were incubated for another $2 \mathrm{~h}$. The absorbance at $450 \mathrm{~nm}$ of each well was measured by a Thermomax Microplate Reader (Bio-Tek EL, USA).

\section{Flow Cytometer Analysis}

Cell apoptosis analysis: The Annexin-V-FITC/PI Apoptosis Detection Kit (Best bio, China) was used to detect RAW264.7 cell apoptosis. RAW264.7 cells were collected in $1.5 \mathrm{~mL}$ centrifuge tubes. In dark conditions, Annexin V binding solution was added to resuspend cells, Annexin V-FITC staining solution was added to react for $15 \mathrm{~min}$ at $4^{\circ} \mathrm{C}$, PI staining solution was added, and the cells were filtered with mesh cloth and transferred to a flow tube.

Cell cycle analysis: The Cell Cycle Analysis Kit (Best Bio, China) was used to detect the cell cycle. RAW264.7 cells were collected in $15 \mathrm{~mL}$ centrifuge tubes and fixed with $80 \%$ ethanol at $-20^{\circ} \mathrm{C}$ for $1 \mathrm{~h}$. Then, the cells were collected in $1.5 \mathrm{~mL}$ centrifuge tubes, $500 \mu \mathrm{L}$ PBS and 20 $\mu \mathrm{L}$ RNase A were added at $37^{\circ} \mathrm{C}$ for $30 \mathrm{~min}$. After that, the cells were filtered with a mesh sieve, $400 \mu \mathrm{L}$ PI dye solution was added to resuspend the cells, and the cells were incubated for 30-60 min in the dark before detection.

\section{CD73 Plasmid Construction}

Mouse pEX-3-CD73 was purchased from Gene Pharma Corporation (Shanghai, China). LipoFiterTM3 (Hanbio, Shanghai, China) was used to transfect pEX-3-CD73 into RAW264.7 cells to overexpress CD73, and the empty vector pEX-3-control was used as a control. Collected cells for further experiments. 


\section{Small RNA Interference (SiRNA) Analysis} siRNA was purchased from Shanghai Gena Pharma Corporation (Gena Pharma, China). Transfection of RAW264.7 cells was conducted with the lipofection technique, using LipoFiterTM3. The siRNA sequences were as follows: The siRNA sequences were as follows: CD73siRNA (sense, 5'-GUGGCACACUUCAUGAACATT-3') and antisense, $\quad 5^{\prime}$-UGUUCAUGAAGUGUGCCACTT-3'); Scrambled-siRNA (sense, 5'-UUCUCCGAACGUGU CACGUTT-3', and antisense, 5'-ACGUGACA CGUUCGGAGAATT). RAW264.7 cells were cultured for $12 \mathrm{~h}$ and then transfected with siRNA. After $6 \mathrm{~h}$, DMEM (10\% FBS) was used instead of Opti-MEM (Gibco, USA), and $100 \mathrm{mM}$ ethanol was added for $36 \mathrm{~h}$.

\section{Cytokine Assay by ELISA}

The serum of mice and the supernatant of RAW264.7 cells were collected. According to the manufacturer's instructions, ELISA kits (Elabscience, Wuhan, China) were used to detect the release of IL- 6 and IL- $1 \beta$. The optical density of the samples was tested by a Thermomax microplate reader at $450 \mathrm{~nm}$.

\section{Western Blotting (WB)}

Total protein was extracted from the tissue or cells with RIPA lysis solution (Beyotime, Shanghai, China) containing 1\% PMSF, and then transferred to the PVDF membranes (BioRad, CA, SDS-PAGE gel (10\%) USA). At room temperature, the membrane was separated with primary antibodies with TBST containing 5\% milk for $3 \mathrm{~h}$, and then the membrane with the primary antibody against $\beta$-actin, CD73, TLR4,

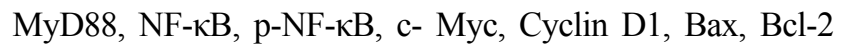
and cleaved caspase 3 overnight at $4{ }^{\circ} \mathrm{C}$ (antibodies used are shown in Table 1). The cells were incubated with HRPconjugated secondary antibodies $(1: 10,000)$ for $1 \mathrm{~h}$ at room temperature the next day after washing three times with TBS/ $\mathrm{T}$ (Tris-buffered saline $+0.05 \%$ Tween 20 ), each time for 10 min. A chemiluminescent (ECL) system (Bio-Rad, USA) was
Table I The Characteristics of Antibodies

\begin{tabular}{|c|c|c|c|}
\hline Protein & Application & Origin & Dilution \\
\hline CD73 & WB\&IF & $\begin{array}{l}\text { Proteintech; United } \\
\text { States }\end{array}$ & $\mathrm{I}: 1000$ \\
\hline$N F-\kappa B$ & WB & Wanlei, China & $\mathrm{I}: 500$ \\
\hline$p-N F-\kappa B$ & WB & Wanlei, China & I:500 \\
\hline MyD88 & WB & Wanlei, China & $\mathrm{I}: 500$ \\
\hline TLR4 & WB & Wanlei, China & I:1000 \\
\hline IL-6 & WB & Affinity, China & $\mathrm{I}: 500$ \\
\hline IL-I $\beta$ & WB & Bioss, China & $\mathrm{I}: 500$ \\
\hline $\begin{array}{l}\text { cleaved- } \\
\text { Caspase3 }\end{array}$ & WB & $\begin{array}{l}\text { Abcam, United } \\
\text { Kingdom }\end{array}$ & $\mathrm{I}: 2000$ \\
\hline $\mathrm{Bax}$ & WB & $\begin{array}{l}\text { Abcam, United } \\
\text { Kingdom }\end{array}$ & I:1500 \\
\hline $\mathrm{Bcl}-2$ & WB & $\begin{array}{l}\text { Abcam, United } \\
\text { Kingdom }\end{array}$ & $\mathrm{I}: 2000$ \\
\hline c-Myс & WB & $\begin{array}{l}\text { Abcam, United } \\
\text { Kingdom }\end{array}$ & $\mathrm{I}: 1000$ \\
\hline CyclinDI & WB & $\begin{array}{l}\text { Abcam, United } \\
\text { Kingdom }\end{array}$ & $1: 1000$ \\
\hline$F 4 / 80$ & IF & $\begin{array}{l}\text { SANTA Cruz, United } \\
\text { States }\end{array}$ & $1: 100$ \\
\hline$\beta$-actin & WB & Bioss, China & $\mathrm{I}: 3000$ \\
\hline
\end{tabular}

used to detect the protein bands, and ImageJ software (National Institutes of Health, USA) was used for analysis.

\section{Quantitative Real-time PCR (RT-qPCR)}

Total RNA was extracted from the tissue or cells by TRIzol (Invitrogen, United States) according to the manufacturer's instructions, and RNA was quantified by a Nanodrop 2000 (Thermo Scientific, USA). Then, cDNA was reverse transcribed with a TaKaRa kit (QIAGEN, Japan). The mRNA levels of $\beta$-actin, CD73, TLR4, MyD88, NF- $\kappa$ B, IL-6 and IL-1 $\beta$ were determined by RT-qPCR (Thermo Scientific, USA). The primer sequence (Sangon Biotech, China) used is shown in Table 2, using $\beta$-actin as a control for the normalization of mRNA expression.

Table 2 RT-qPCR Primers

\begin{tabular}{|l|l|l|}
\hline Gene & \multicolumn{1}{|c|}{ Forward } & \multicolumn{1}{c|}{ Reverse } \\
\hline$\beta$-actin & AGTGTGACGTTGACATCCGT & TGCTAGGAGCCAGAGCAGTA \\
CD73 & CTGAGCGCTCTACTACCACA & AACAGCACGTTGGGTTCTTC \\
TLR4 & ATGGCATGGCTTACACCACC & GAGGCCAATTTTGTCTCCACA \\
MyD88 & GCATGGTGGTGGTTGTTTCT & TCTGTTGGACACCTGGAGAC \\
NF-KB & CCTCTCTCGTCTTCCTCCAC & GTTTGCGGAAGGATGTCTCC \\
IL-6 & GGAGCCCACCAAGAACGATA & GTTGTCACCAGCATCAGTCC \\
IL-I $\beta$ & AAGAGCCCATCCTCTGTGAC & AGCTCATATGGGTCCGACAG \\
\hline
\end{tabular}




\section{Statistical Analysis}

All results were expressed as mean \pm standard deviation using GraphPad Prism (San Diego, California). Student's $t$-test or one-way analysis of variance (LSD) were used for statistical significance test, the significance was as follows: ${ }^{*} P,{ }^{\#} P<0.05,{ }^{* *} P,{ }^{\# \#} P<0.01$, ***P, ${ }^{\# \# \#} P<0.001$.

\section{Results}

\section{EtOH-Fed Mice Had Higher Levels of CD73 Than Pair-Fed Mice}

In the alcoholic liver injury and inflammation model, we observed that the weight of mice in the EtOH-fed group was reduced, and the liver index was increased (Figure 1B

$\mathbf{A}_{2}$

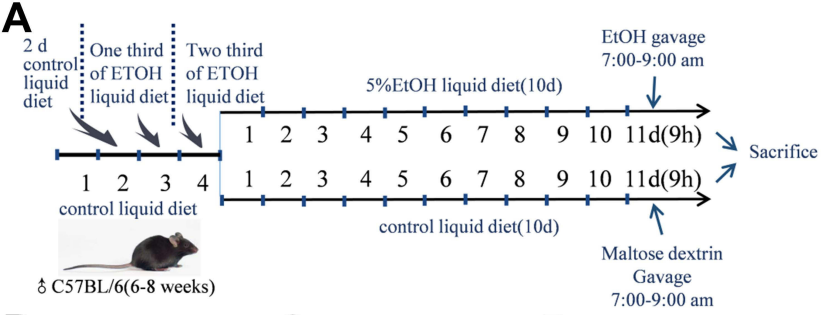

B

B

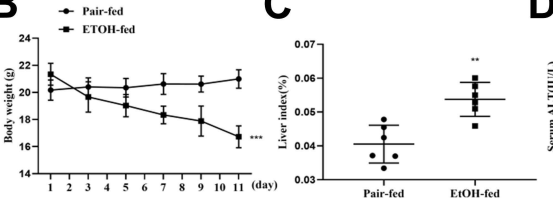

D

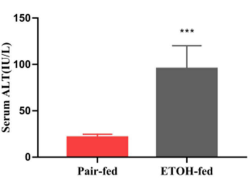

E
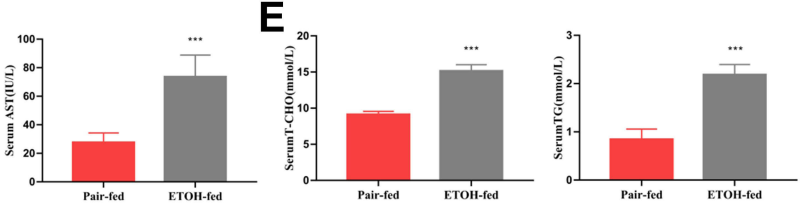

$\mathbf{F}$
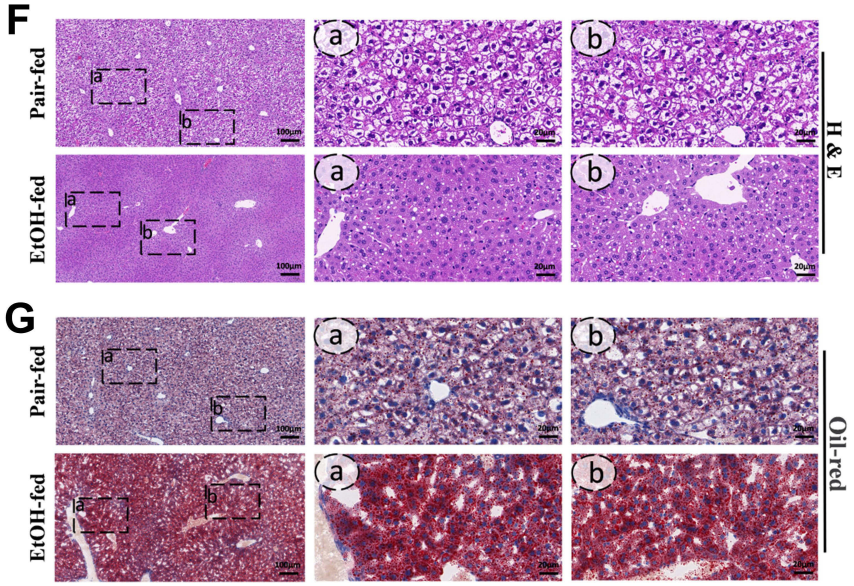

and C). From Figure 1F, G and H, we could see that the liver cords were arranged disorderly, with fat vacuoles and a large amount of fat accumulation. At the same time, the serum levels of ALT, AST, T-CHO and TG increased (Figure $1 \mathrm{D}$ and $\mathrm{E}$ ). The immunohistochemistry results showed that the positive expression of IL-1 $\beta$ and IL-6 was significantly increased (Figure 1I and J). The RTqPCR and ELISA results also showed that the expression of IL-6 and IL-1 $\beta$ was significantly increased after alcohol stimulation (Figure $1 \mathrm{~K}$ and $\mathrm{L}$ ). These results indicate that the model was successfully established. To determine whether CD73 participates in alcohol-induced liver injury and inflammation, we detected the expression level of CD73 in mice after chronic and binge $\mathrm{EtOH}$ feeding.
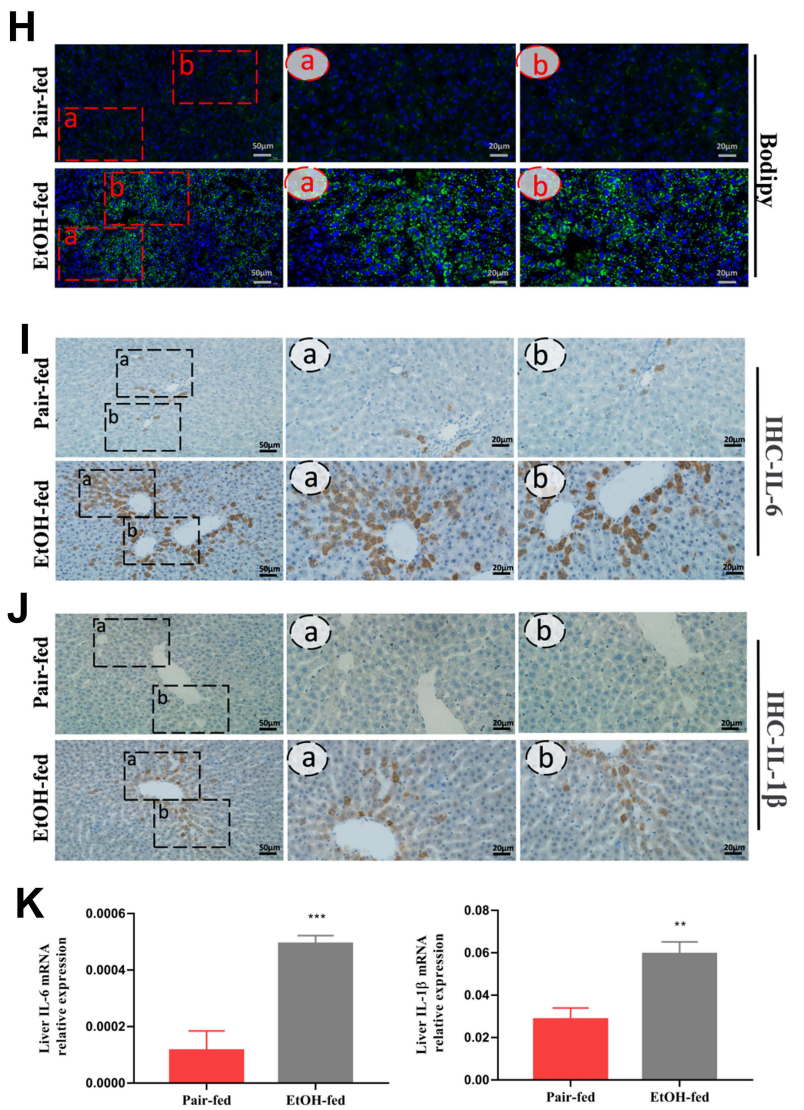

$\mathbf{L}$
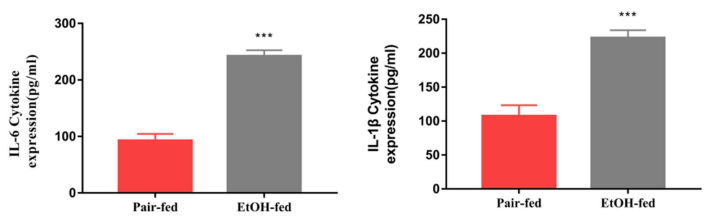

Figure I EtOH-fed mice had higher levels of CD73 than pair-fed mice. (A) The process of alcohol-induced liver injury and inflammation. (B) Body weight loss, $\mathrm{n}=6$. (C) Liver index increases, $n=6$. (D) Serum ALT and AST levels, $n=5-6$. (E) Hepatic TG and T-CHO levels, $n=5-6$. (F) Representative H\&E staining of liver sections (I00 $\mu$ m, 20 $\mu \mathrm{m})$. (G) Representative Oil Red O staining of liver sections (100 $\mu \mathrm{m}, 20 \mu \mathrm{m})$. (H) Representative BODIPY staining of liver sections (50 $\mu \mathrm{m}, 20 \mu \mathrm{m})$. (I) The expression of IL-6 was detected by IHC $(50 \mu \mathrm{m}, 20 \mu \mathrm{m})$. (J) The expression of IL-I $\beta$ was detected by IHC $(50 \mu \mathrm{m}, 20 \mu \mathrm{m})$. (K) The mRNA levels of IL-6 and IL-I $\beta$ in the liver. (L) The release of the inflammatory cytokines IL- 6 and IL-I $\beta$ from serum was measured by ELISA. $* * P<0.01$, $* * * P<0.001$ compared with the pair-fed group. 
Western blotting and RT-qPCR showed that the expression level of CD73 was upregulated in EtOH-fed mice compared to pair-fed mice (Figure 2A and B). The results of IHC further proved that the expression of CD73 was increased in the EtOH-fed group (Figure 2C). Double immunofluorescence staining showed that the CD73positive area and F4/80-positive area overlapped, which indicated that CD73 was expressed in macrophages (Figure 2D).

\section{The Expression of CD73 Was Increased in EtOH-Primed RAW264.7 Cells}

To induce inflammation, RAW264.7 cells were stimulated with EtOH at different times and concentrations. First, RAW264.7 cells were treated with different concentrations of EtOH for $24 \mathrm{~h}$ and CCK 8 was used to detect the viability of cells. The CCK8 results showed that when the EtOH concentration was lower than $200 \mathrm{mM}$, there was no significant difference in cell viability (Figure 3A).

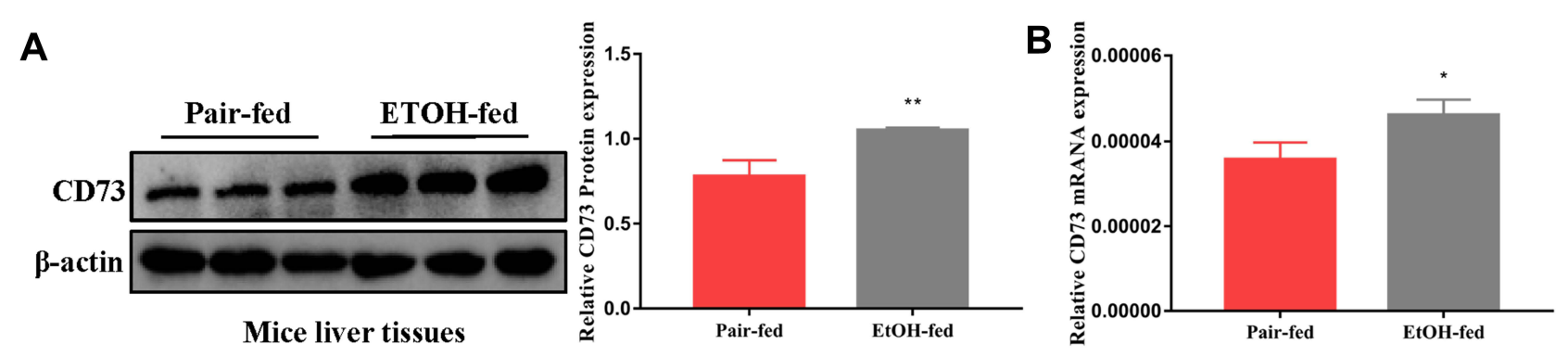

C
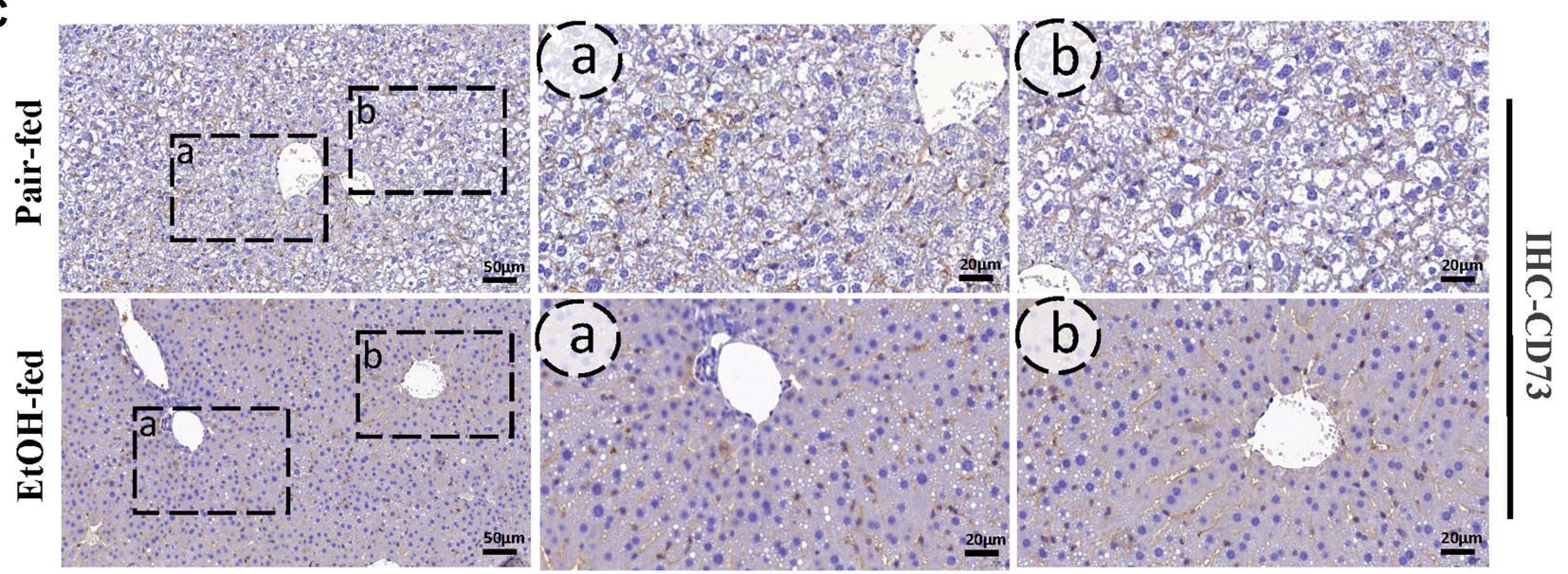

D

DAPI

CD73

F4/80

Merge

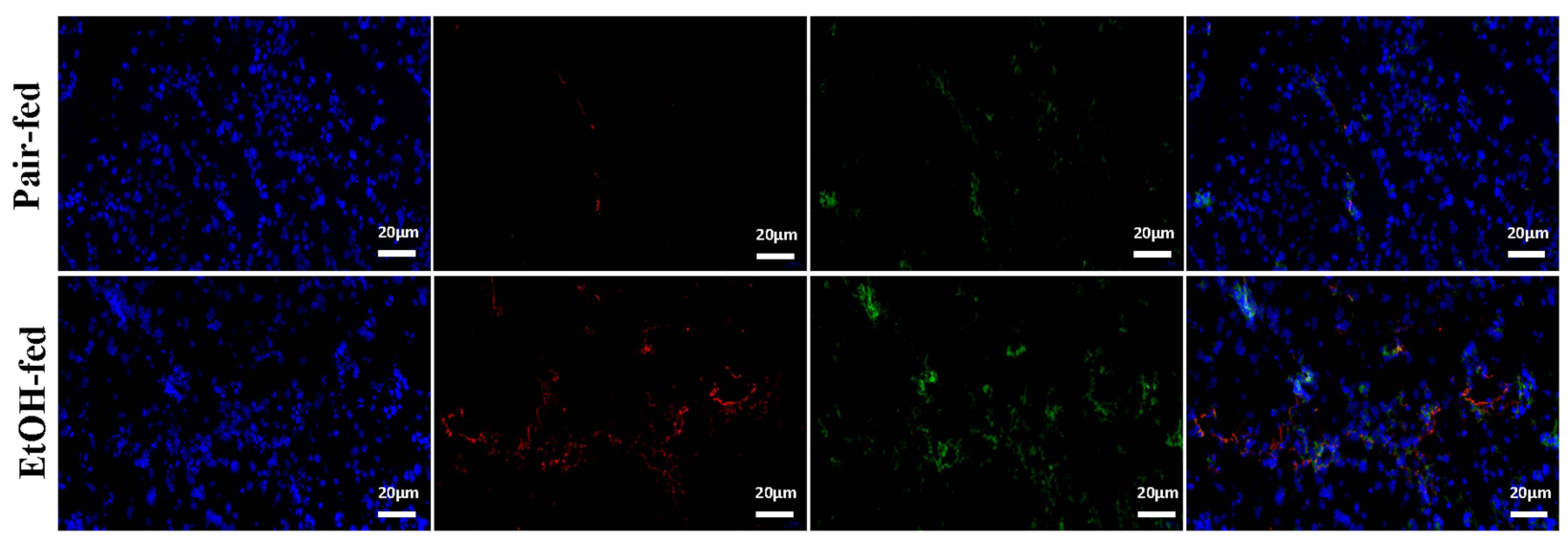

Figure 2 The expression of CD73 was increased in EtOH-primed RAW264.7 cells (A) The protein level of CD73 in the liver. (B) The mRNA level of CD73 in the liver. (C) The expression of CD73 was detected by IHC (50 $\mu \mathrm{m}, 20 \mu \mathrm{m})$. (D) Double immunofluorescence staining of CD73 (red) and F4/80 (green); representative views from the pair-fed group and EtOH-fed group were presented $(20 \mu \mathrm{m})$. $* P<0.05, * * P<0.01$ compared with the pair-fed group. 
A

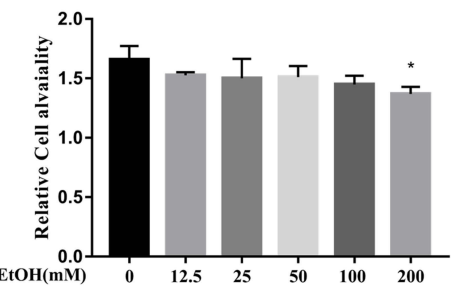

C

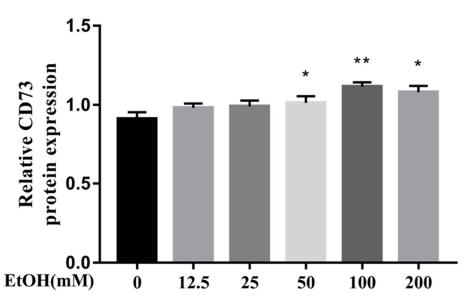

E

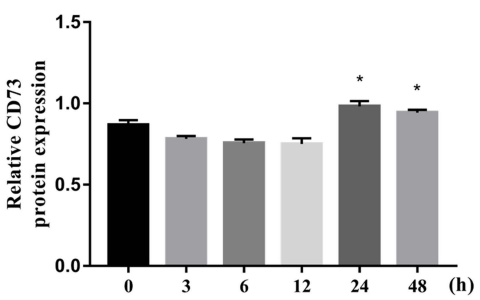

G

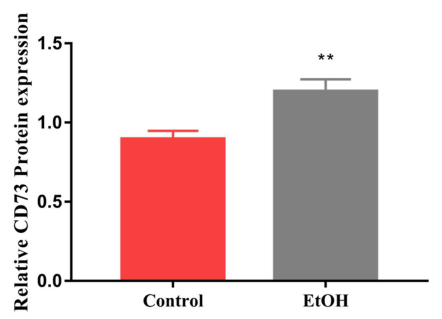

I

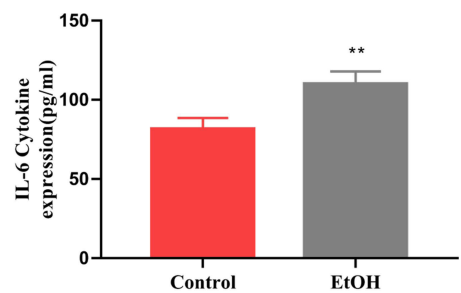

J

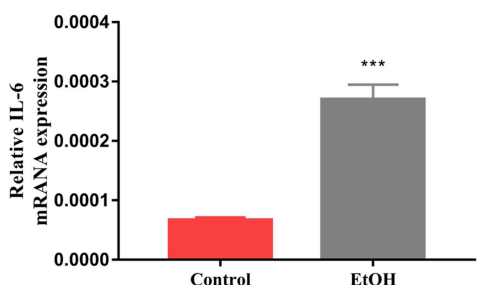

B

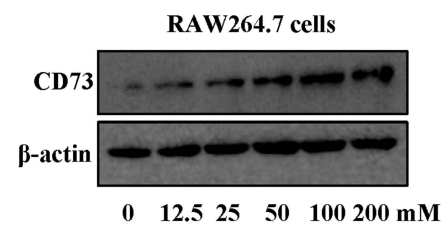

D

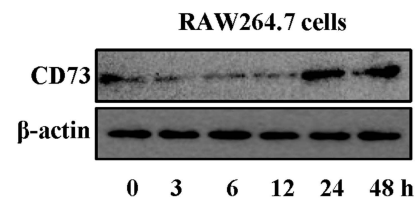

F

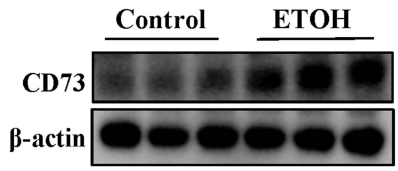

RAW264.7 cells

H
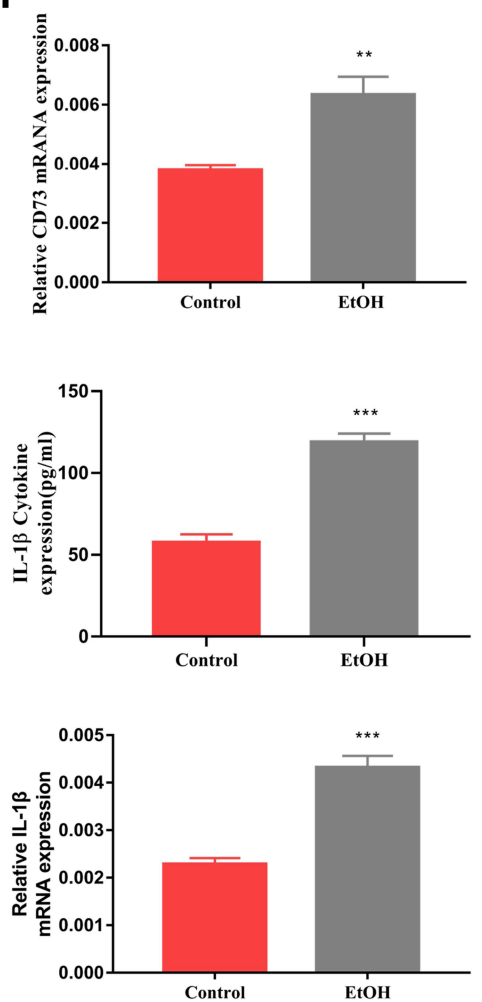

Figure 3 The expression of CD73 was increased in EtOH-primed RAW264.7 cells. (A) Effect of different concentrations of EtOH on RAW264.7 cell viability by CCK-8 assay. (B and C) The protein level of CD73 in RAW264.7 cells. $* P<0.05$, $* * P<0.01$ compared with 0 mM. (D and E) The protein level of CD73 in RAW264.7 cells. *P $<$ 0.05 compared with $0 \mathrm{~h}$. (F and $\mathbf{G})$ The protein level of CD73 in RAW264.7 cells. (H) The mRNA level of CD73 in RAW264.7 cells. (I) The release of the inflammatory cytokines IL-6 and IL-I $\beta$ from RAW264.7 cells into serum was measured by ELISA. (J) The mRNA levels of IL- 6 and IL-I $\beta$ in the liver. $* * P<0.0$ I, $* * * P<0.00$ I compared with the control group. 
Second, the Western blotting results showed that the expression level of CD73 was upregulated with increasing EtOH induction and reached the highest protein level at $100 \mathrm{mM}$ after $24 \mathrm{~h}$ of EtOH stimulation (Figure 3B and C). At the same time, Western blotting results showed that the expression of $\mathrm{CD} 73$ reached a peak at $24 \mathrm{~h}$ after $\mathrm{EtOH}$ stimulation (Figure 3D and E). Therefore, we stimulated cells with $100 \mathrm{mM} \mathrm{EtOH}$ for $24 \mathrm{~h}$ to detect the level of CD73. Western blotting and RT-qPCR results showed that the expression of $\mathrm{CD} 73$ in the EtOH group was higher than that in the control group (Figure $3 \mathrm{~F}, \mathrm{G}$ and $\mathrm{H}$ ). In addition, IL- 6 and IL- $1 \beta$ were significantly upregulated in EtOH-treated RAW264.7 cells (Figure 3I and J).

\section{CD73 Inhibited the Secretion of IL-6 and IL-I $\beta$ in EtOH-Primed RAW264.7 Cells}

The extracellular nucleotidases CD39 and CD73 are key regulatory molecules in the purine signaling pathway that can hydrolyze the ATP released outside the cell into adenosine. Our previous research showed that the expression of CD39 was increased in the EtOH-fed group, but silencing CD39 reduced the inflammation caused by EtOH in RAW264.7 cells. Therefore, we believe that although the expression of CD73 is increased in the EtOH-fed group, its role in alcoholic steatohepatitis is still uncertain. So we first determined its role in RAW264.7 cells. The pEX3CD73 plasmid and CD73-siRNA were transfected to increase and inhibit CD73 expression in RAW264.7 cells. Figure $4 \mathrm{~A}$ and $\mathrm{B}$ showed the overexpression and knockdown effects of CD73. It can be seen from the results of RT-qPCR and ELISA that upregulation of CD73 strongly decreased the secretion of IL- 6 and IL-1 $\beta$ induced by EtOH (Figure 4C). Meanwhile, when the expression of CD73 was inhibited, the expression of IL-6 and IL-1 $\beta$ was increased (Figure 4D). In summary, overexpression of $\mathrm{CD} 73$ can reduce inflammation caused by EtOH.

\section{Overexpression of CD73 Alleviated Alcohol-Induced Liver Injury and Inflammation}

To further determine the role of CD73 in alcohol-induced liver injury and inflammation, we injected rAAV9-CD73 via the tail vein to overexpress CD73 in mice. rAA9-emptyGFP was successfully delivered to liver tissue via the tail vein through a small animal in-vivo imaging system (Figure 5A). The results of Western blotting, RT-qPCR and
IHC further proved the overexpression of CD73 in the liver (Figure $5 \mathrm{G}, \mathrm{H}, \mathrm{J}$ and $\mathrm{K}$ ). Compared with the EtOH-fed group, rAAV9-CD73 significantly reduced the liver index and ALT, AST, T-CHO and TG levels in mice (Figure 5BD). The results of H\&E and BODIPY staining showed that alcohol-induced liver cell cord derangement, intercellular space dilatation, increased fatty vacuoles and lipid accumulation were greatly improved by rAAV9-CD73 (Figure 5E and $\mathrm{F}$ ). In addition, we found that rAAV9-CD73 treatment restrained alcohol-induced protein and mRNA levels of IL-6 and IL-1 $\beta$ in liver tissues and primary macrophages (Figure 5I-K). These results indicated that the overexpression of CD73 can reduce alcohol-induced liver injury, lipid accumulation and inflammation.

\section{CD73 Inhibited Apoptosis and Promoted Proliferation in RAW264.7 Cells Primed with $\mathrm{EtOH}$}

To explore whether CD73 has an effect on the apoptosis and proliferation of RAW264.7 cells, we overexpressed CD73. We detected the expression of proteins related to apoptosis (Bax, Bcl-2, and cleaved caspase 3) and proliferation (c-Myc and CyclinD1). The Western blotting results showed that the ratio of Bax/Bcl-2 and the expression of cleaved-caspase 3 decreased with increasing CD73 expression, which illustrated that overexpression of CD73 could inhibit the apoptosis of RAW264.7 cells. The flow cytometry results also proved this view (Figure $6 \mathrm{~A}$ and $\mathrm{B}$ ). The protein expression of $\mathrm{c}-\mathrm{Myc}$ and CyclinD1 in the pEX3-CD73 group was significantly higher than that in the pEX3-NC group, indicating that increasing CD73 expression promoted the proliferation of RAW264.7 cells (Figure 7B). Flow cytometry showed that activated RAW264.7 cells entered G2/M phase in the pEX3-CD73 + EtOH group (Figure 7A). To further explore the effect of CD73 on the apoptosis and proliferation of RAW264.7 cells, CD73-siRNA was used. The results of Figure 6D showed that the ratio of $\mathrm{Bax} / \mathrm{Bcl}-2$ and the protein expression of cleaved-caspase 3 were upregulated by inhibiting CD73. The results of Figure $6 \mathrm{C}$ showed that silencing CD73 increased the percentage of apoptotic cells in activated RAW264.7 cells. In addition, compared with the scrambled-siRNA+EtOH group, c-myc and CyclinD1 were decreased in the CD73-siRNA+EtOH group (Figure 7D). Flow cytometry also showed that compared with the scrambled-siRNA+EtOH group, the CD73-siRNA + EtOH group observably induced cell cycle arrest in G0/ 
A

B

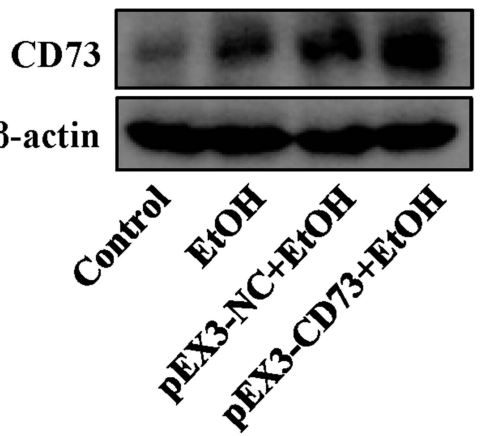

C
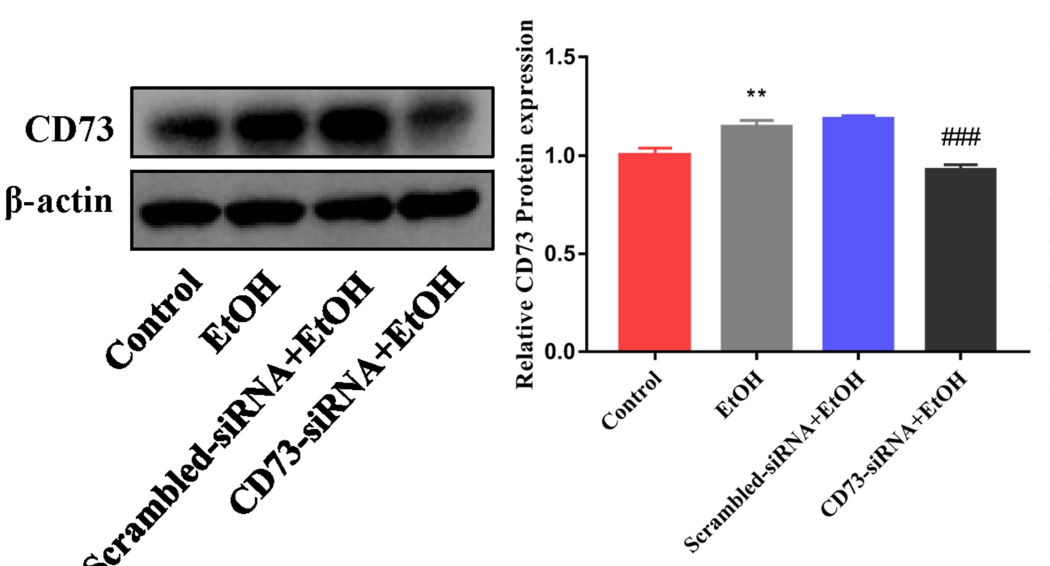
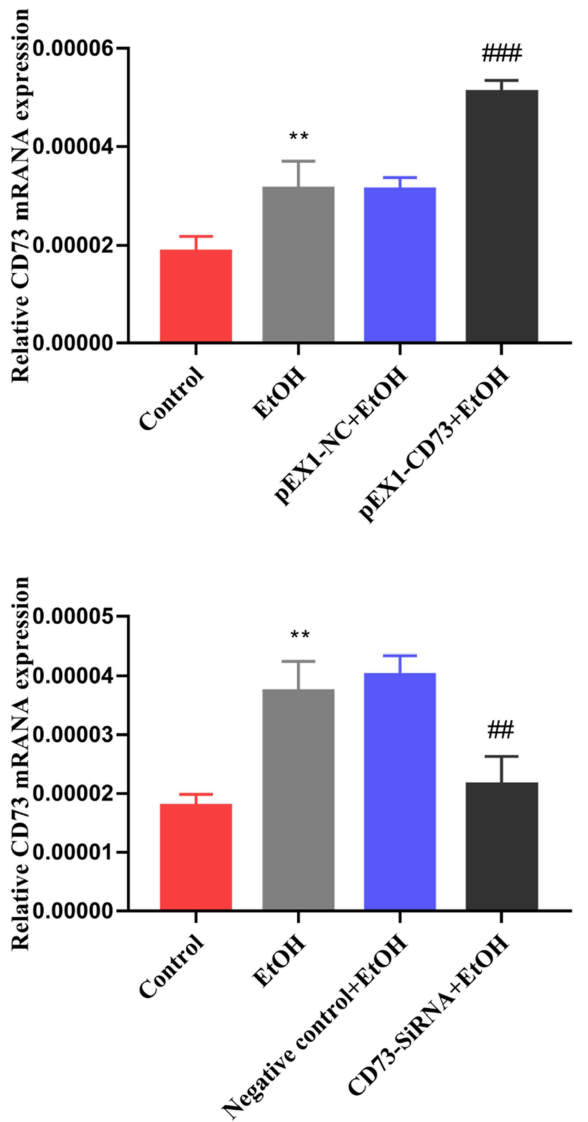

D
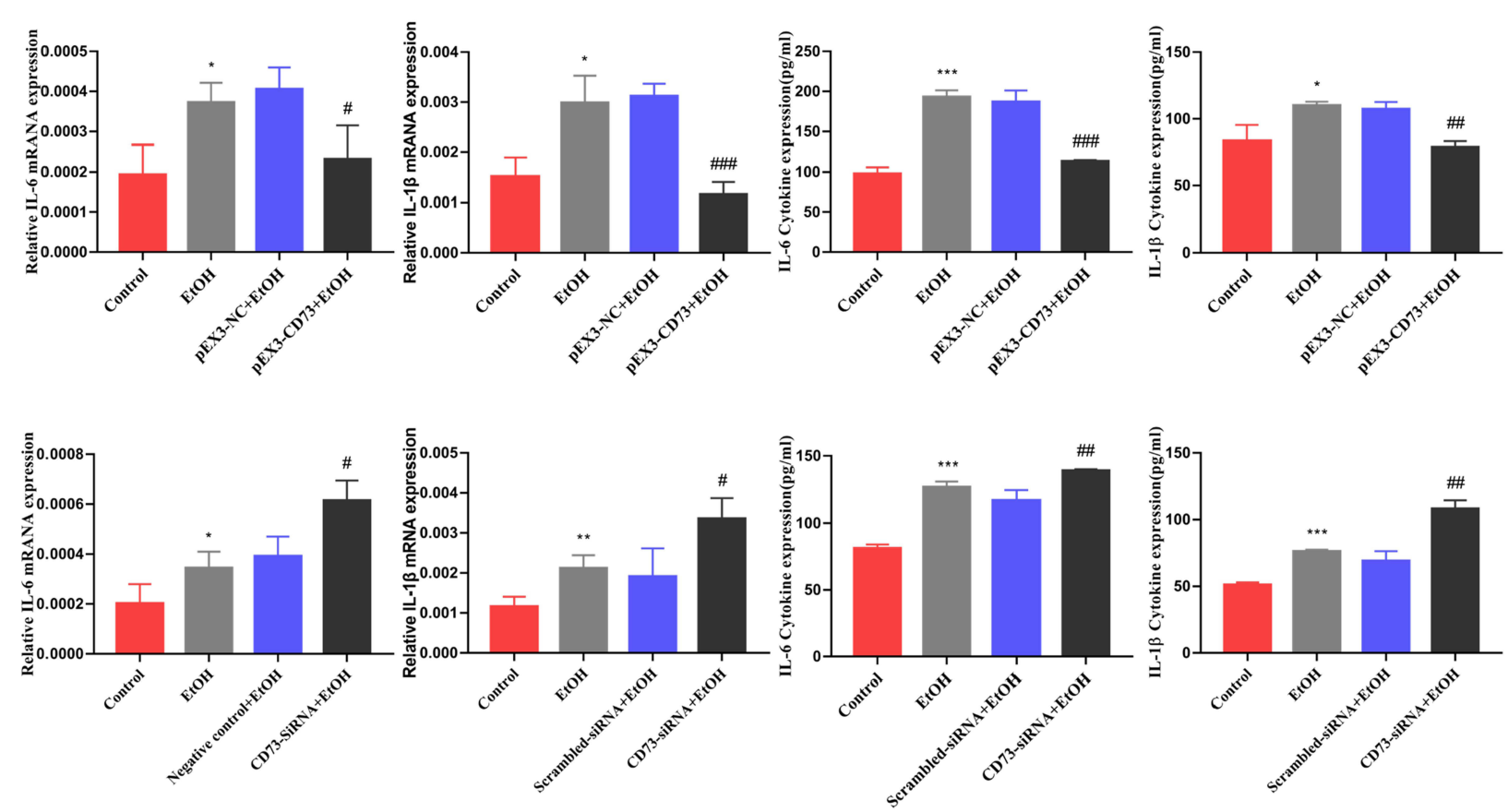

Figure 4 CD73 inhibited the secretion of IL-6 and IL-I $\beta$ in RAW264.7 cells induced by EtOH. (A) The protein and mRNA levels of CD73 in RAW264.7 cells. **P < 0.0 I compared with the control group. ${ }^{\#} p<0.01,{ }^{\# \#} p<0.001$ compared with the pEX3-NC+EtOH group. (B) The protein and mRNA levels of CD73 in RAW264.7 cells. $* * P<$ 0.01 compared with control group. ${ }^{\#} P<0.0$ I, ${ }^{\# \#} P<0.00$ I compared with the scrambled-siRNA+EtOH group. (C) The levels of proinflammatory cytokines (IL-6 and IL-I $\beta$ ) in culture supernatants were determined by ELISA, and the mRNA levels of IL- 6 and IL-I $\beta$ in RAW264.7 cells. *P< 0.05 , $* * * P<0.00$ I compared with the control group. ${ }^{\#} P<$ $0.05,{ }^{\#} P<0.01,{ }^{\#} P<0.00$ I compared with the $P E X 3-N C+E t O H$ group. (D) The levels of proinflammatory cytokines (IL-6 and IL-I $\beta$ ) in culture supernatants were determined by ELISA, and the mRNA levels of IL- 6 and IL-I $\beta$ in RAW264.7 cells. $* P<0.05$, ${ }^{* * P}<0.0$ I, $* * * P<0.00$ I compared with the control group. ${ }^{\#} P<0.05$, ${ }^{\#} P<0.01$ compared with the scrambled-siRNA+EtOH group. 


\section{A}
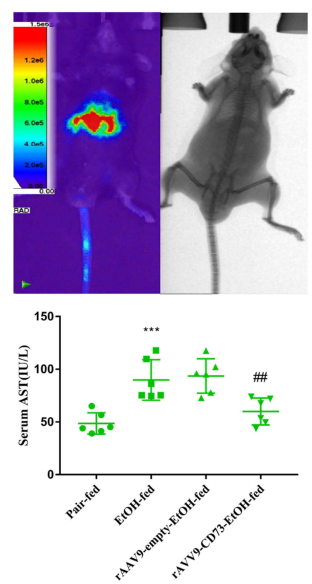

B

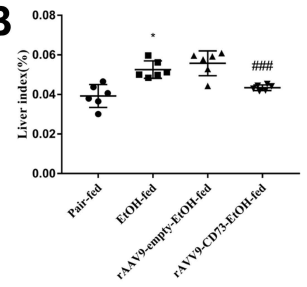

D
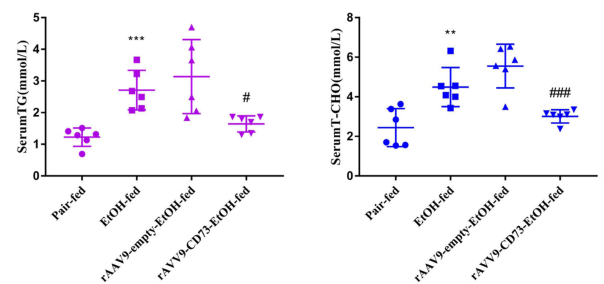

E

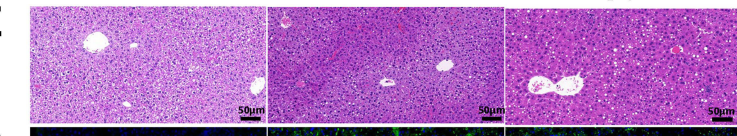

F

G

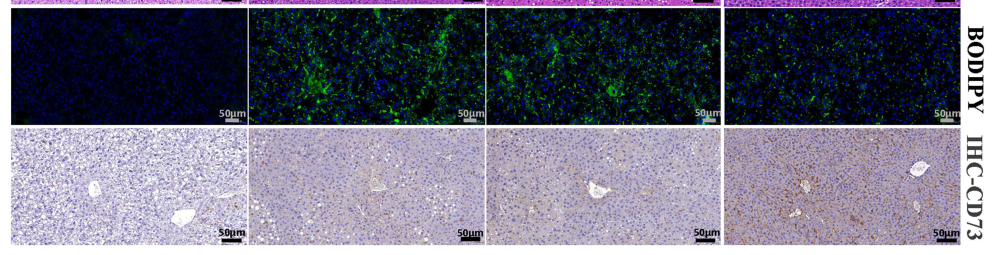

H

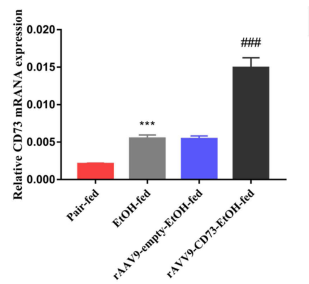

J

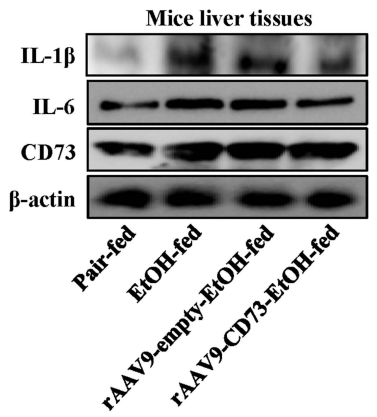

K

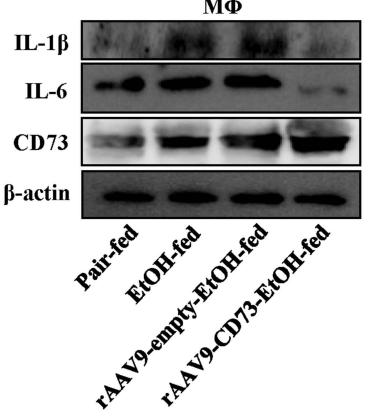

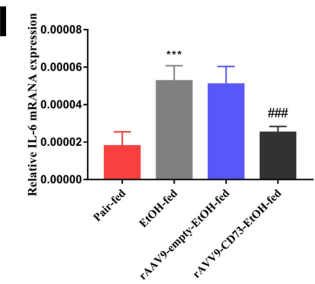
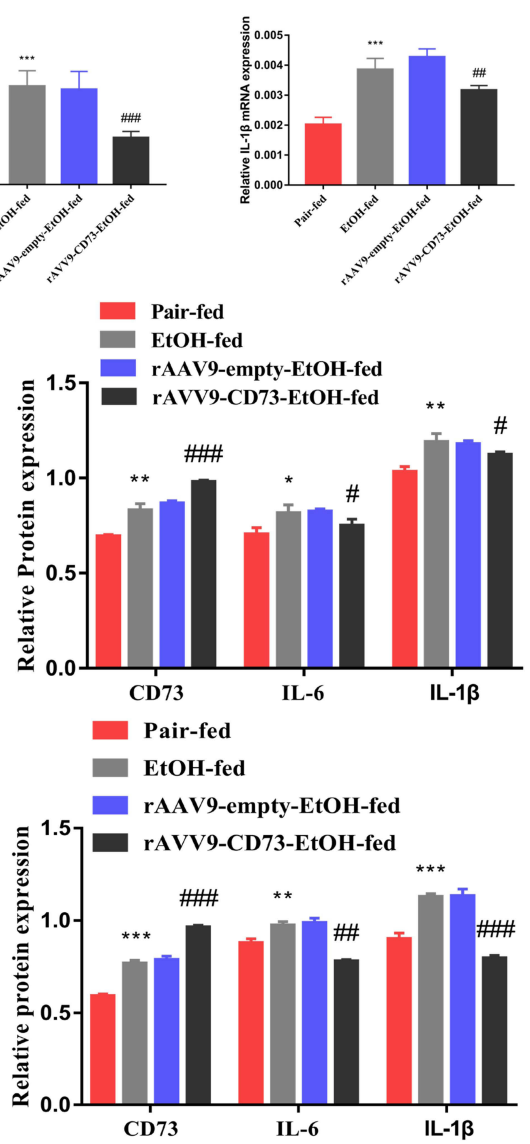

Figure 5 rAAV9-CD73 protected against alcohol-induced liver injury and inflammation. (A) Small animal in-vivo imaging system. (B) Liver index, $\mathrm{n}=6$. (C) Serum ALT and AST levels, $n=5-6$. (D) Hepatic TG and T-CHO levels, $n=5-6$. (E) Representative H\&E staining of liver sections (50 $\mu \mathrm{m})$. (F) Representative BODIPY staining of liver sections $(50 \mu \mathrm{m})$. (G) The expression of CD73 was detected by IHC $(50 \mu \mathrm{m})$. (H) The mRNA level of CD73 in the liver. (I) The mRNA levels of IL-6 and IL-I $\beta$ in the liver. (J) The protein levels of CD73, IL- 6 and IL-I $\beta$ in the liver. (K) The protein levels of CD73, IL- 6 and IL-I $\beta$ in primary macrophages. $* P<0.05$, $* * P<0.0$ I, $* * * P<0.00$ I compared with the pair-fed group. ${ }^{\#} P<0.05,{ }^{\#} P<0.01,{ }^{\#} P<0.001$ compared with the rAAV9-empty-EtOH-fed group. 

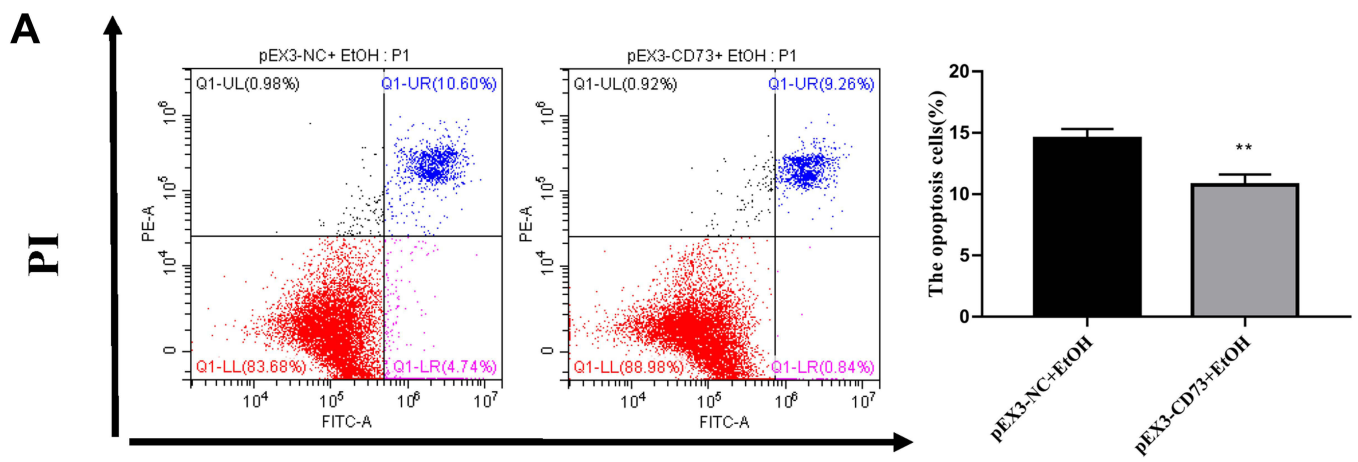

\section{AV-FITC}

B
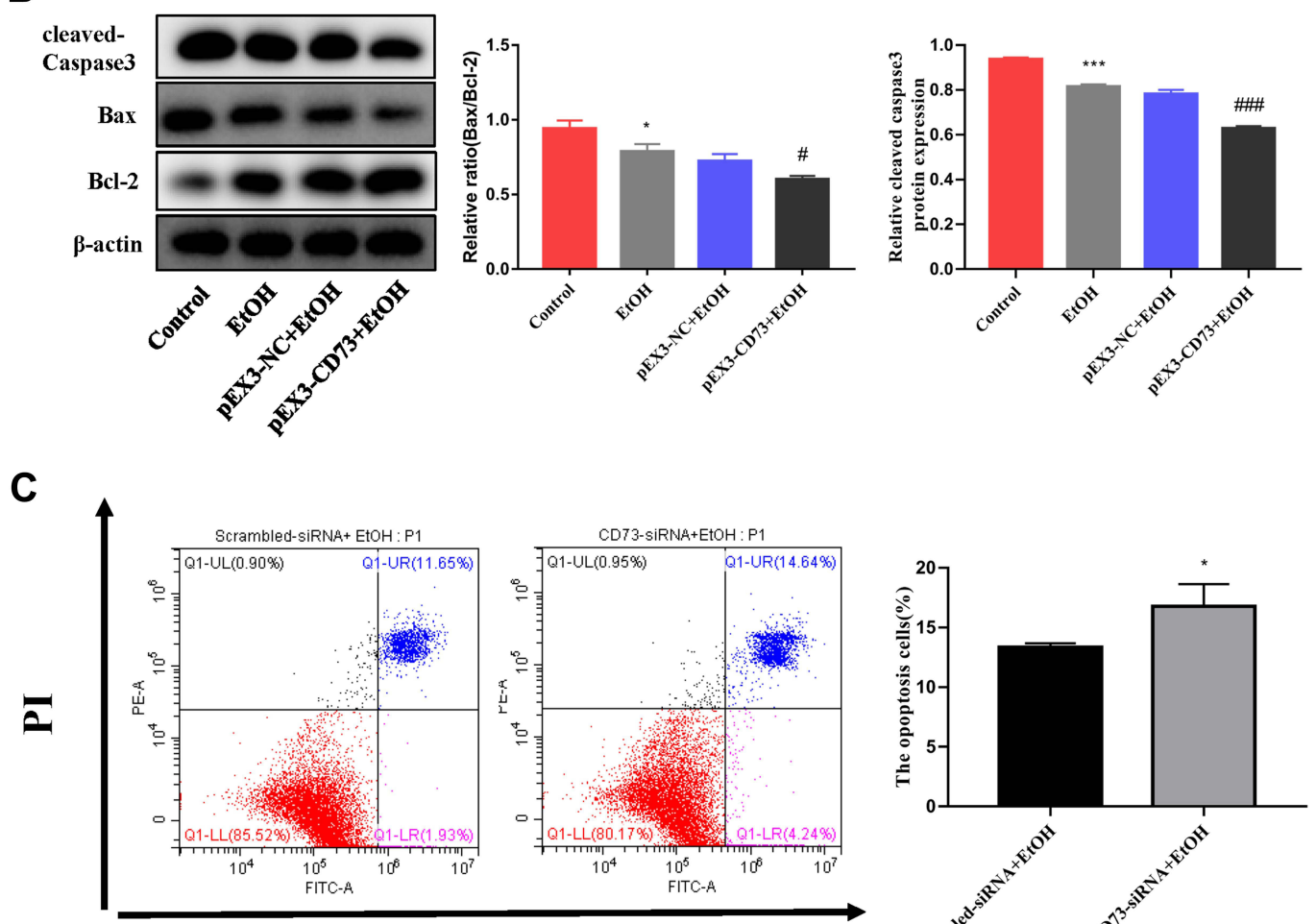

D

\section{AV-FITC}
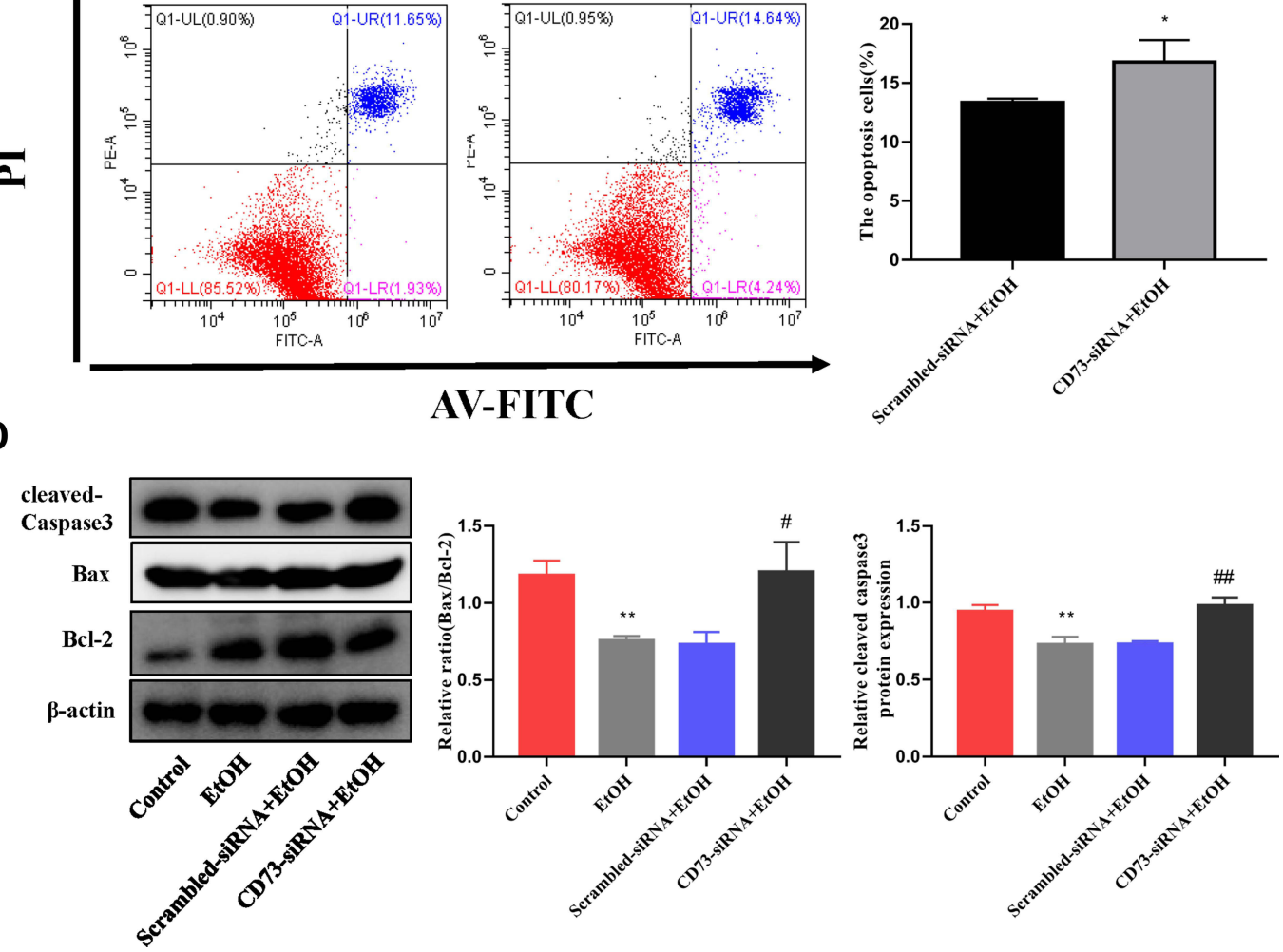

Figure 6 CD73 inhibits the apoptosis of RAW264.7 cells. (A) The effect of increased CD73 on the apoptosis of EtOH-activated RAW264.7 cells was determined by flow cytometry. **P $<0.01$ compared with the $p E X 3-\mathrm{NC}+\mathrm{EtOH}$ group. (B) Expression of Bax, Bcl-2 and cleaved caspase-3 in RAW264.7 cells transfected with the $\mathrm{pEX} 3-\mathrm{CD} 73$. $* \mathrm{P}<$ 0.05 , ***P $<0.001$ compared with the control group. ${ }^{\#} P<0.05,{ }^{\#} p<0.001$ compared with the $p E X 3-N C+E t O H$ group. (C) The effect of decreased CD73 on the apoptosis of EtOH-activated RAW264.7 cells was determined by flow cytometry. $* P<0.05$ compared with the scrambled-siRNA+EtOH group. (D) Expression of Bax, Bcl-2 and cleaved caspase-3 in RAW264.7 cells transfected with CD73-siRNA. ${ }^{* * P}<0.01$ compared with the control group. ${ }^{\#} P<0.05,{ }^{\#} P<0.01$ compared with the Scrambled-siRNA+EtOH group. 
A
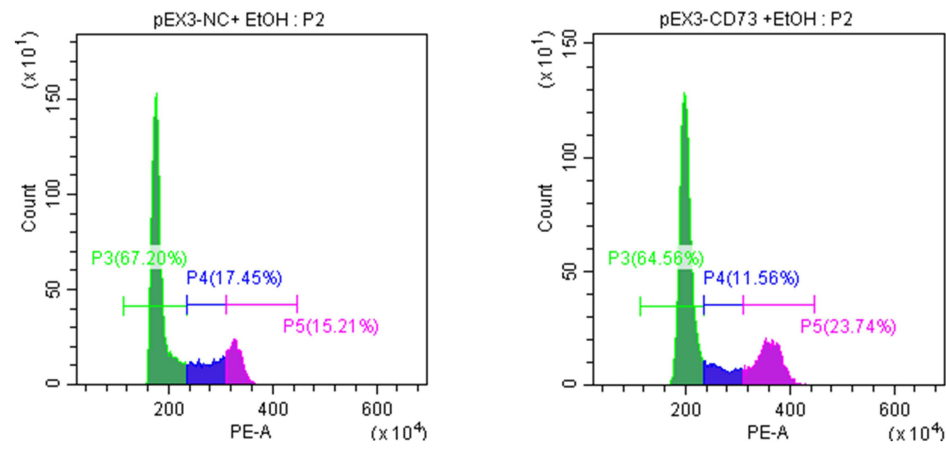

B
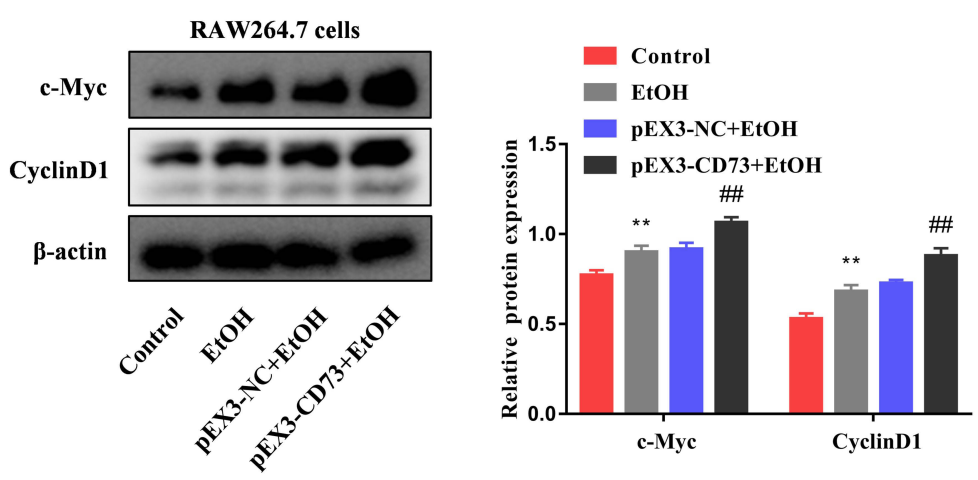

C
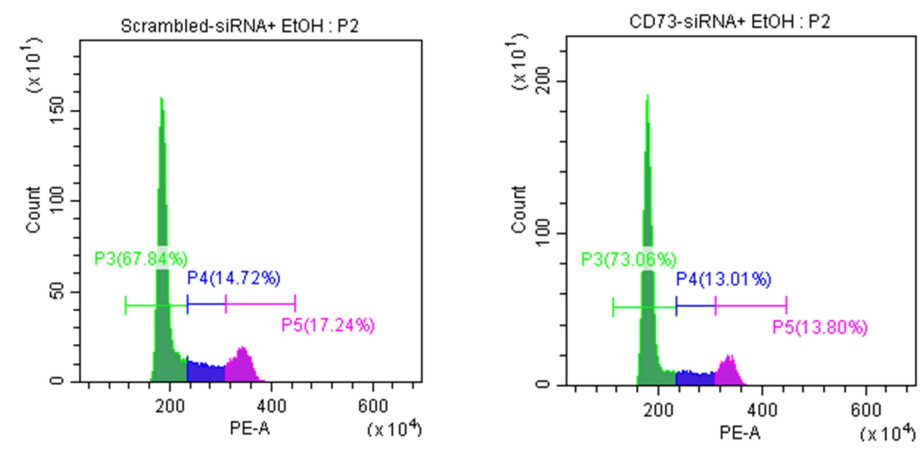

D
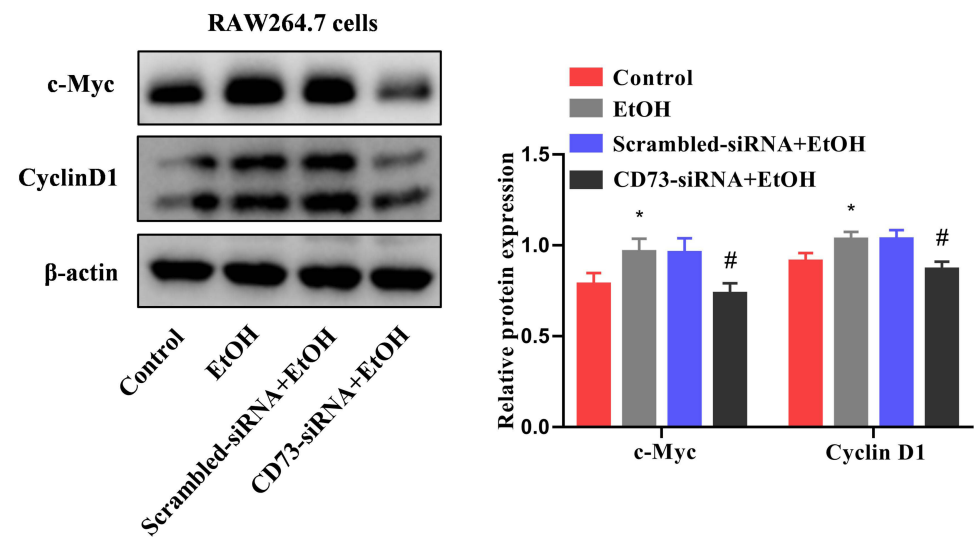

Figure 7 CD73 promotes the proliferation of RAW264.7 cells. (A) The effect of increased CD73 on the proliferation of EtOH-activated RAW264.7 cells was determined by flow cytometry. (B) Expression of c-Myc and CyclinDI in RAW264.7 cells transfected with pEX3-CD73. **P < 0.01 compared with control group. ${ }^{\#} P<0.01$ compared with the pEX3-NC+EtOH group. (C) The effect of decreased CD73 on the proliferation of EtOH-activated RAW264.7 cells was determined by flow cytometry. (D) Expression of c-Myc and CyclinDI in RAW264.7 cells transfected with CD73-siRNA. ${ }^{*} P<0.05$ compared with control group. ${ }^{\#} P<0.05$ compared with the scrambledsiRNA+EtOH group. 
G1 accompanied by an obvious reduction in cell numbers in the G2/M phase in RAW264.7 cells (Figure 7C). In conclusion, overexpression of CD73 can inhibit apoptosis and promote the proliferation of RAW264.7 cells.

\section{Overexpression of CD73 Blocked TLR4/ MyD88/NF- $\kappa B$ Signaling Pathway}

Evidence indicates that TLR4/MyD88/NF- $\kappa B$ signaling pathway is a key regulator involved in inflammatory processes. ${ }^{27,28}$ From Figure 8A, B, E and F, we can see that the protein expression of TLR4, MyD88 and p- NF$\kappa \mathrm{B}$ is significantly increased in EtOH-fed group mice liver tissues and EtOH-primed RAW264.7 cells. To further explore the regulatory role of CD73 on the TLR4/ MyD88/NF- $\mathrm{KB}$ signaling pathway, we silenced and overexpressed CD73. The results showed that the expression of TLR4, MyD88 and p-NF-kB in the pEX3-NC+EtOH group was down regulated in EtOH-primed RAW264.7 cells transfected with pEX3-CD73 (Figure 8C and G). In contrast, when CD73-siRNA was applied, it was observed that the expression of TLR4, MyD88 and p-NF- $\mathrm{kB}$ increased (Figure 8D and $\mathrm{H}$ ). These results emphasized that CD73 overexpression blocked the TLR4/MyD88/NF$\kappa \mathrm{B}$ signaling pathway in alcoholic liver disease.

\section{CD73 Regulated the Inflammatory Response and Apoptosis in $\mathrm{EtOH}$ - Treated RAW 264.7 Cells Through TLR4/ MyD88/NF- $\kappa B$ Signaling Pathway}

To confirm the role of TLR4/MyD88/NF- $\mathrm{BB}$ signaling pathway in the observed protective effects of CD73 overexpression on ALD, we inhibited the expression of TLR4 in pEX3-CD73 mimic- transfected RAW 264.7 cells, and then observed the secretion of inflammatory cytokines and apoptosis. First, we used a CCK 8 kit to detect the viability of RAW264.7 cells treated with different concentrations of TAK242 (a specific inhibitor of TLR4). Figure 9A showed that when the concentration was lower than 100 $\mathrm{ng} / \mathrm{mL}$, the cell viability was not significantly affected. Thus we chose concentrations of TAK242 of 2.5, 10, 25 and $50 \mathrm{ng} / \mathrm{mL}$ and selected a concentration of TAK 242 of $2.5 \mathrm{ng} / \mathrm{mL}$ for the subsequent experiments (Figure 9B). The results in Figure 9C showed that overexpression of CD73 significantly inhibited the expression of IL- $1 \beta$ and IL-6 induced by EtOH, while inhibiting TLR4 further enhanced this inhibitory effect. In addition, overexpression of CD73 reduced apoptosis and promoted the proliferation of RAW264.7 cells. On this basis, inhibiting the expression of TLR4 further promoted the proliferation and inhibited the apoptosis of RAW264.7 cells (Figure 9D-G). In conclusion, these results indicated that overexpression of $\mathrm{CD} 73$ inhibited the release of inflammatory cytokines and apoptosis, at least in part through its downregulation of the TLR4/MyD88/NF- $\mathrm{BB}$ axis (Figure 10).

\section{Discussion}

Alcoholic liver disease (ALD) is caused by long-term heavy drinking and can be divided into simple fatty liver, alcoholic hepatitis, liver fibrosis and cirrhosis. ${ }^{29}$ Cell damage, inflammation, oxidative stress, regeneration and bacterial translocation are the key drivers of alcoholic liver damage. Alcoholic hepatitis is considered to be the most serious form of liver damage caused by alcohol. However, to date, there is no better treatment except for abstinence from alcohol. ${ }^{30}$ Massive evidence of ALD will emphasize monocyte recruitment and macrophage polarization and differentiation, proliferation inhibition, and macrophage activation in the liver. Monocytes and macrophages have become potential therapeutic targets for ALD. ${ }^{31}$ However, the potential mechanism that promotes the proliferation of macrophages needs to be further explored.

Macrophages (MФ) plays a key role in liver injury and inflammation during the development of ALD disease. ${ }^{32}$ Alcohol consumption increases the translocation of intestinal endotoxin to portal circulation and the activation of Kupffer cells (hepatic macrophages) via the lipopolysaccharide/TLR4 pathway. Activated KCs release proinflammatory cytokines and chemokines, leading to a series of inflammatory reactions, including the release of inflammatory cytokines such as tumor necrosis factor $\alpha($ TNF $-\alpha)$ and interleukin-6 (IL-6), which eventually lead to liver injury. ${ }^{33,34}$ According to macrophage functional status, macrophages are divided into M1 and M2. ${ }^{35}$ M1 macrophages produce proinflammatory and stress mediators and cytokines, such as IL-1 and tumor necrosis factor alpha $(\mathrm{TNF} \alpha)$. When the damage is controlled, it will convert to M2 macrophages. M2 macrophages are responsible for inhibiting the secretion of proinflammatory cytokines, including TNF- $\alpha$, IL- 6 , and IL- $1 \beta^{36-39}$ Therefore, the current academic view believes that M2 macrophages dominate in mild liver damage and steatosis, while M1 macrophages appear in severe liver damage. ${ }^{40}$ As a key regulatory molecule in the purine signaling pathway, CD73 has been found to play an 
A

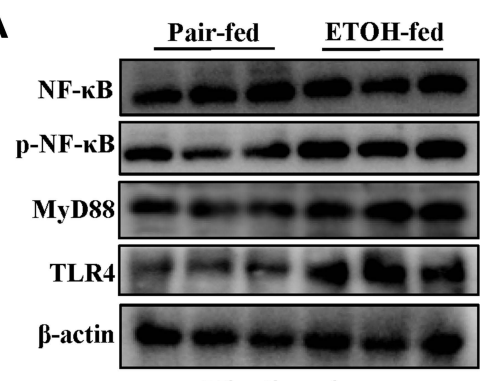

Mice liver tissues

C

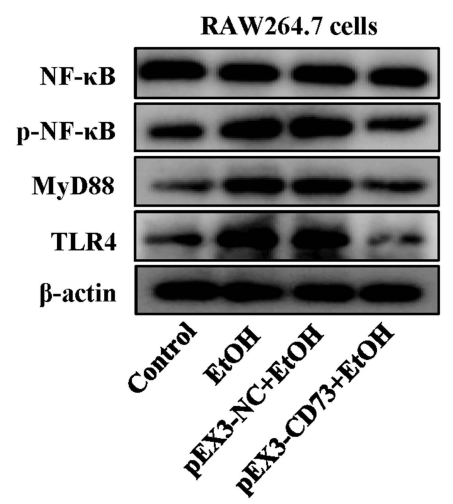

E

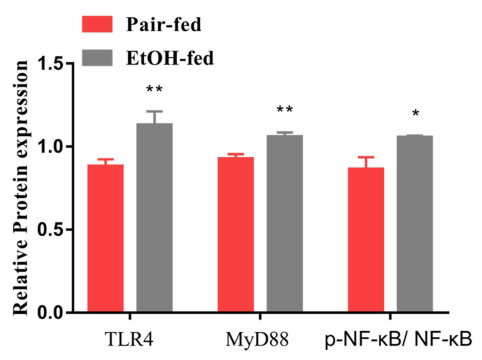

B

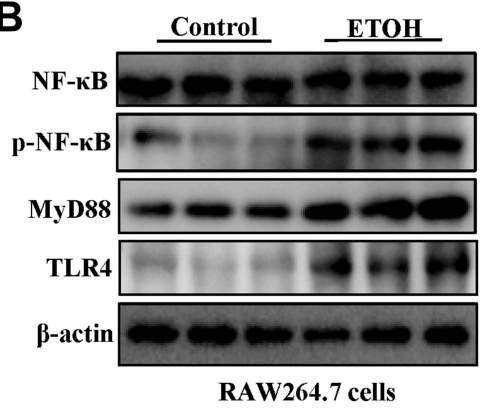

D

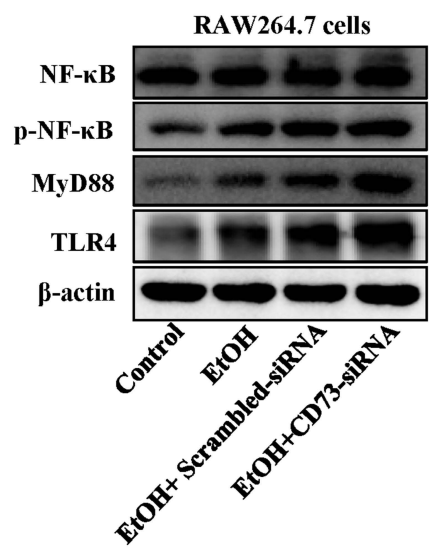

F

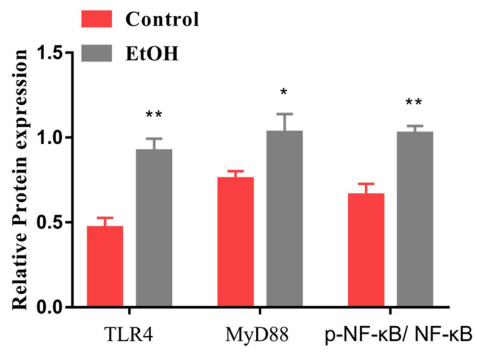

G

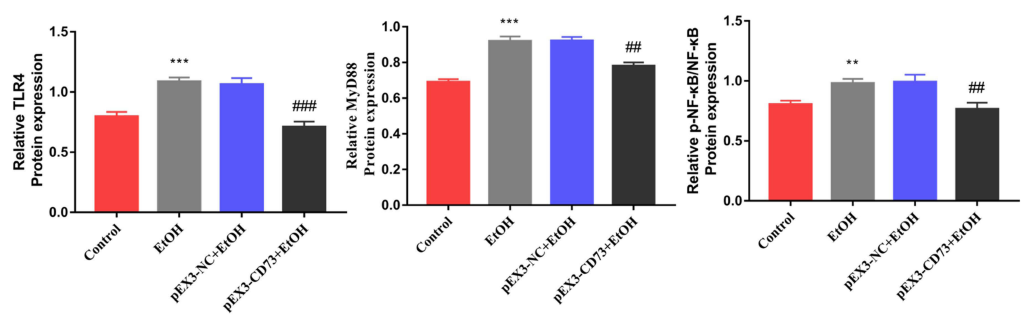

H

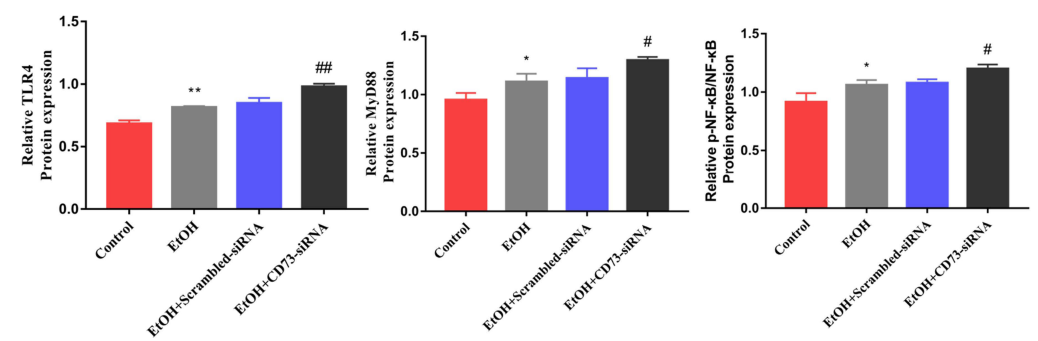

Figure 8 Overexpression of CD73 blocked the TLR4/MyD88/NF- $\kappa B$ signaling pathway. (A and E) The protein levels of TLR4, NF- $\kappa B$, $p-N F-\kappa B$ and MyD88 in the liver. $* P<$

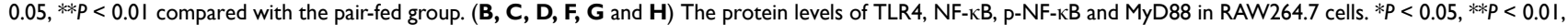
*** $P<0.001$ compared with the control group. ${ }^{\#} p<0.05,{ }^{\#} p<0.01,{ }^{\# \#} p<0.001$ compared with $p E X 3-\mathrm{NC}+\mathrm{EtOH} / \mathrm{scrambled}-\mathrm{siRNA}+\mathrm{EtOH}$ group. 
A

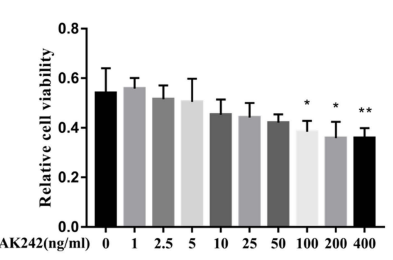

$\mathbf{B}$

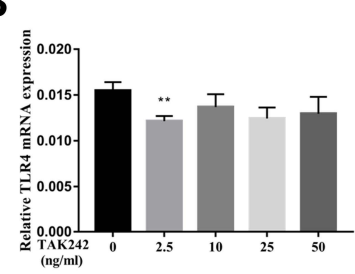

C

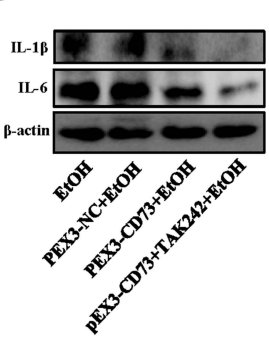

D

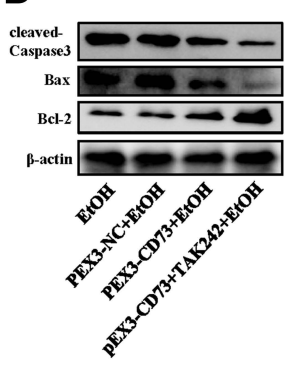

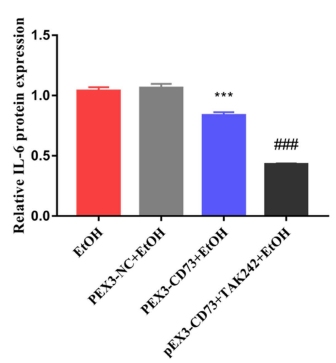
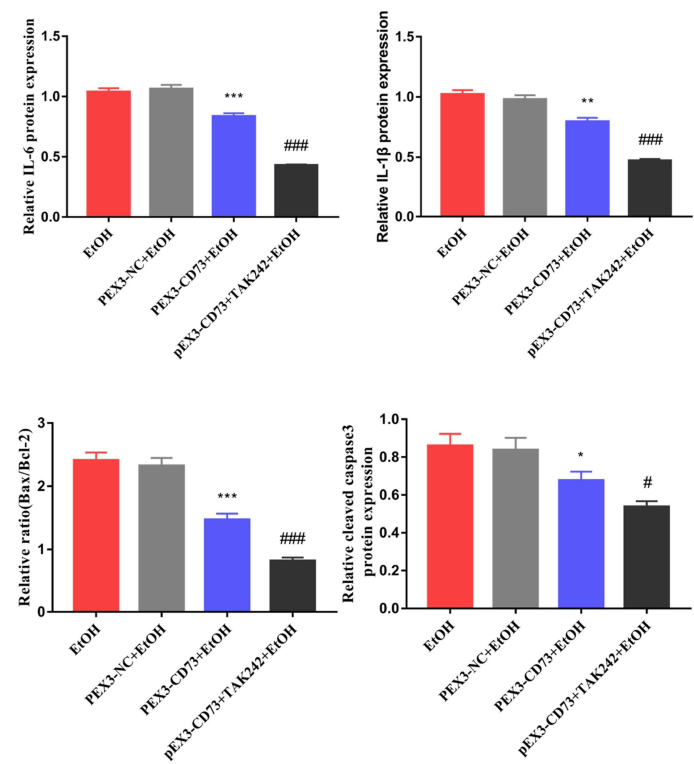
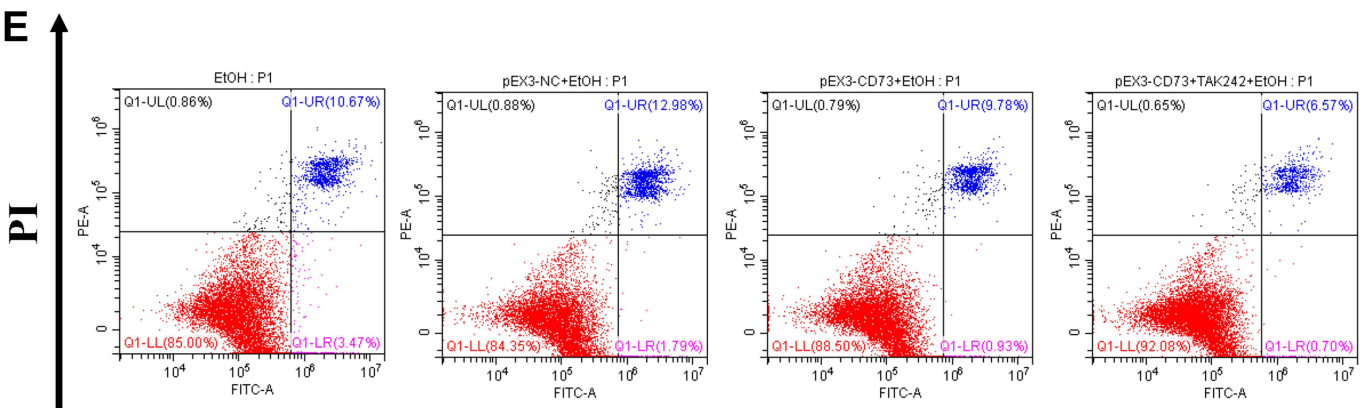

AV-FITC
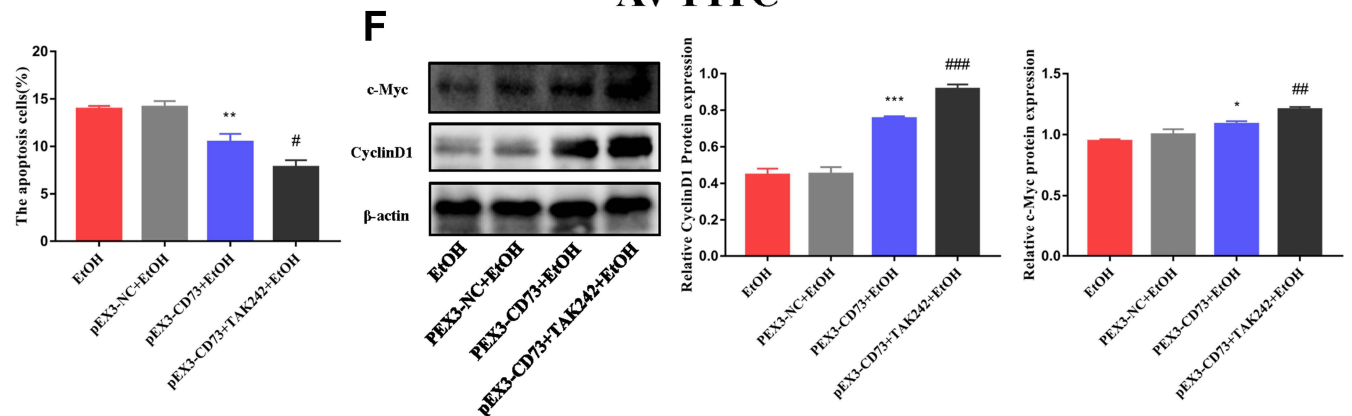

$\mathbf{G}$
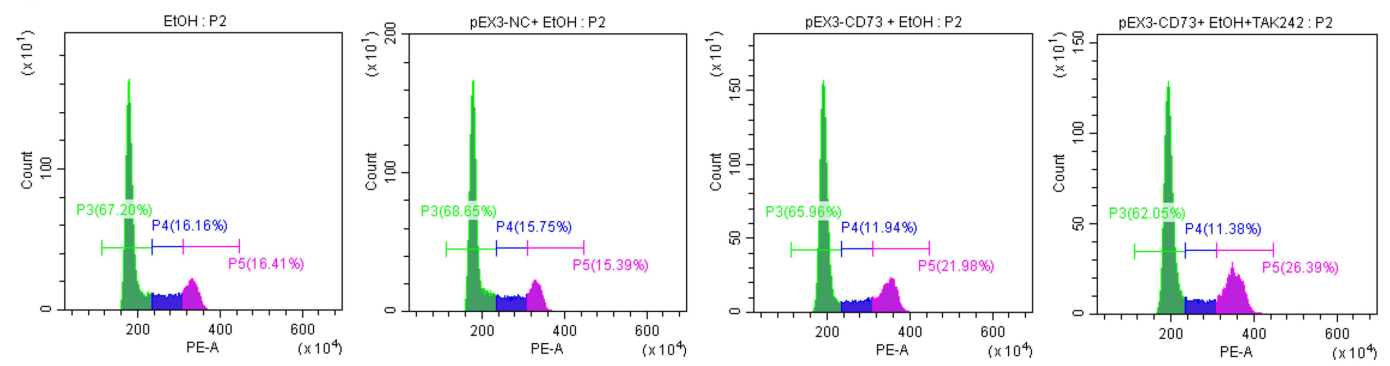

Figure $9 \mathrm{CD} 73$ regulates the inflammatory response and apoptosis in EtOH treated RAW 264.7 cells through TLR4/MyD88/NF-kB. (A) Effect of different concentrations of TAK242 on RAW264.7 cell viability by CCK-8 assay. $* P<0.05$, $* * P<0.01$ compared with $0 \mathrm{ng} / \mathrm{mL}$. (B) The mRNA level of TLR4 in RAW264.7 cells. **P $<0.01$ compared with $0 \mathrm{ng} /$ $\mathrm{mL}$. (C) The protein levels of IL-6 and IL-I $\beta$ in RAW264.7 cells. (D) Expression of Bax, Bcl-2 and cleaved caspase-3 in RAW264.7 cells. (E) The apoptosis of RAW264.7 cells was determined by flow cytometry. (F) Expression of c-Myc and CyclinDI in RAW264.7 cells. $* P<0.05, * * P<0.01, * * * P<0.00$ I compared with the $p E X 3-N C+E$ tOH group. ${ }^{\#} P<0.05$, ${ }^{\# P} P<0.01,{ }^{\prime \prime} P<0.001$ compared with the $P E X 3-C D 73+T A K 242+E t O H$ group. (G) The proliferation of RAW264.7 cells was determined by flow cytometry. 


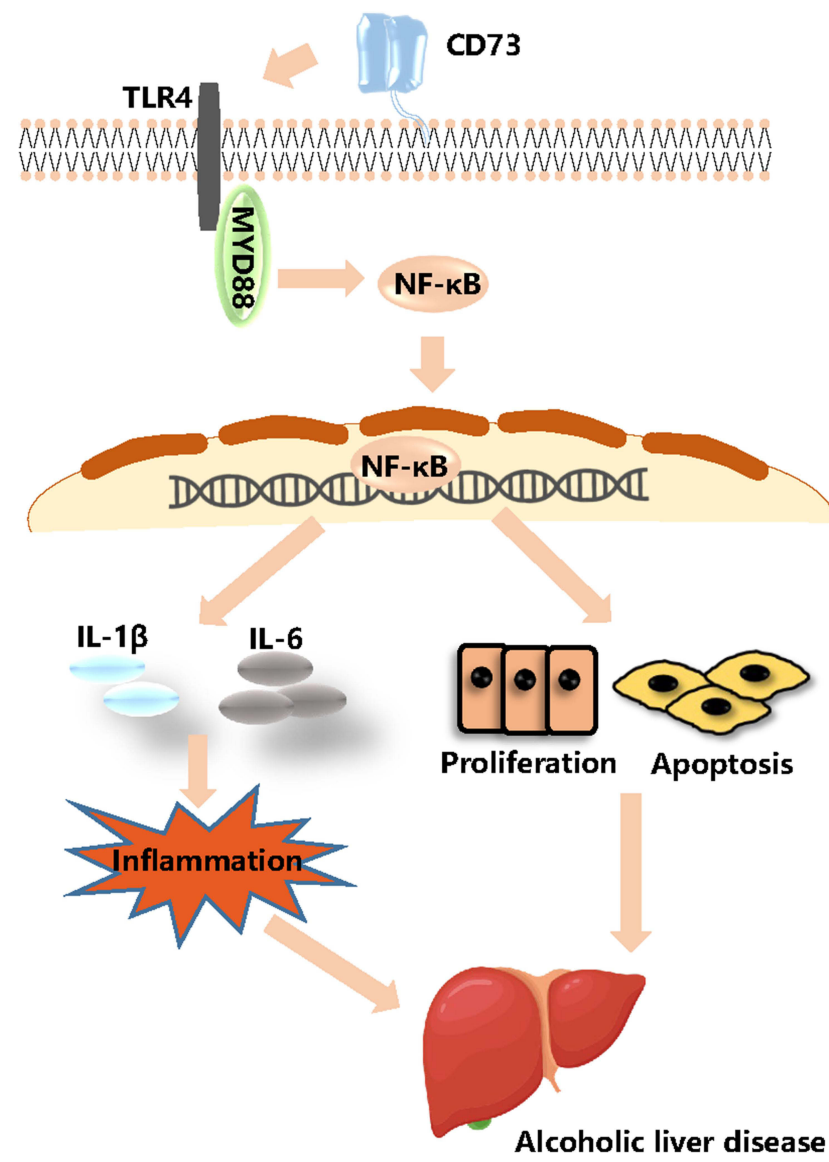

Figure 10 CD73 inhibited the release of inflammatory cytokines and RAW264.7 cell apoptosis through downregulation of the TLR4/MyD88/NF- $\kappa B$ signaling pathway.

important role in a variety of inflammatory diseases. For example, it can prevent vascular inflammation and play a protective role in neuroinflammation caused by ischemic stroke, but it promotes inflammation in experimental autoimmune encephalomyelitis. ${ }^{41-43}$ This shows that its mechanism of mediating tissue damage has not yet been completely resolved. In addition, studies have shown that human macrophages with M1 macrophages express lower levels of CD73 than M2 macrophages, and inhibiting macrophage apoptosis can alleviate ALD. ${ }^{44,45}$ To date, there is no research on CD73 in alcohol-induced liver injury and inflammation, especially in RAW264.7 cells. In this study, we evaluated the role of CD73 during ALD and further explored the inherent mechanism in RAW264.7 cells.

Our experimental results showed that CD73 increased in mice in the EtOH-fed group and EtOH-primed RAW264.7 cells, which indicates that CD73 may play a crucial role in alcohol-induced liver injury and inflammation and EtOH-induced RAW264.7 cells. At the same time, the results of immunohistochemistry, ELISA and RT-qPCR showed that the expression of IL-6 and IL$1 \beta$ increased in mice in the EtOH-fed group and EtOHprimed RAW264.7 cells. Interestingly, when we silenced CD73 in vitro, EtOH primed inflammation was aggravated. When we overexpressed CD73 in RAW264.7 cells, both IL- 6 and IL-1 $\beta$ expression was downregulated. In response to this phenomenon, according to previous research on the purine signaling pathway, we thought that ATP mainly played a proinflammatory role by binding to the P2 receptor in alcohol-induced liver injury and inflammation, CD73 was a rate-limiting enzyme that hydrolyzed ATP, and its expression increased feedback. Therefore, we injected rAAV9-CD73 into the mice, H\&E and BODIPY staining showed that the liver damage of the mice was relieved. The expression of IL- 6 and IL- $1 \beta$ was significantly downregulated in the rAAV9-CD73 group. We obtained the same conclusion in primary macrophages from mouse livers. In addition, we observed that silencing CD73 inhibited the proliferation and promoted the apoptosis of RAW264.7 cells. Importantly, the function of CD73 in cell proliferation and apoptosis was reversed by CD73 knockdown. Based on these experimental data, we can draw the conclusion that CD73 is crucial to the secretion of proinflammatory cytokines and the proliferation and apoptosis of RAW264.7 cells.

TLR4 is an important member of the TLRs family. TLR-4 and its unique ligand can activate MyD88 and $\mathrm{NF}-\kappa \mathrm{B}$, and then induce the expression of inflammatory cytokines such as TNF- $\alpha$, IL- 6 and IL-1 $\beta$. According to reports, IL-I $\beta$ needs to be cleaved by caspase- 1 to convert the precursor IL-I $\beta$ into an active form. The inflammasome is necessary for the activation of caspase-1. ${ }^{46}$ The role of inflammasomes in the anti-inflammatory effects of CD73 has also aroused our thinking and provided a possible direction for future experiments. Recent experiments

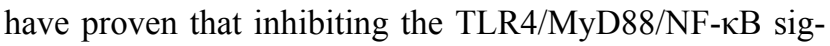
naling pathway can reduce liver inflammation. ${ }^{47,48}$ Previous transcriptome sequencing results in HSCs also showed that changes in the expression of CD73 will have a significant impact on the NF- $\kappa \mathrm{B}$ and Toll-like receptor signaling pathways. In this study, we observed that the expression of the TLR4/MyD88/NF- $\kappa \mathrm{B}$ signaling pathway was upregulated under EtOH stimulation, both in vivo and in vitro. Then, we used pEX3-CD73 and CD73 siRNA to overexpress and silence CD73 in RAW264.7 cells. The 
results showed that silencing CD73 increased the expression of the TLR4/MyD88/NF- $\kappa \mathrm{B}$ signaling pathway. When CD73 was overexpressed, the levels of the TLR4/ MyD88/NF- $\mathrm{B}$ signaling pathway were reduced. More importantly, after adding a specific inhibitor of TLR4 on the basis of CD73 overexpression, the levels of inflammatory cytokines and RAW264.7 cell apoptosis were further suppressed. Overall, these findings indicate that CD73 inhibited the secretion of inflammatory cytokines and RAW264.7 cell apoptosis by blocking the TLR4/MyD88/ $\mathrm{NF}-\kappa \mathrm{B}$ signaling pathway.

\section{Conclusion}

In conclusion, our study confirmed that CD73 can improve liver injury and inflammation induced by EtOH, inhibit apoptosis and promote the proliferation of RAW264.7 cells. Its mechanism of action is at least partially related to the inhibition of the TLR4/MyD88/NF- $\kappa \mathrm{B}$ signaling pathway. This work provides evidence in support of the use of CD73 as a potential therapeutic medicine for alcoholic liver disease.

\section{Funding}

This study was supported by the National Natural Science Foundation of China (No. 81970518).

\section{Disclosure}

The authors declare that there are no conflicts of interest.

\section{References}

1. Wang Y, Liu Y, Kirpich I, et al. Lactobacillus rhamnosus GG reduces hepatic TNF $\alpha$ production and inflammation in chronic alcohol-induced liver injury. J Nutr Biochem. 2013;24(9):1609-1615. doi:10.1016/j. jnutbio.2013.02.001

2. Arsene D, Farooq O, Bataller R. New therapeutic targets in alcoholic hepatitis. Hepatol Int. 2016;10(4):538-552. doi:10.1007/s12072-0159701-6

3. Liangpunsakul S, Haber P, McCaughan G. Alcoholic liver disease in Asia, Europe, and North America. Gastroenterology. 2016;150 (8):1786-1797. doi:10.1053/j.gastro.2016.02.043.

4. Wang FS, Fan JG, Zhang Z, Gao B, Wang HY. The global burden of liver disease: the major impact of China. Hepatology. 2015;60 (6):2099-2108.

5. Addolorato G, Mirijello A, Barrio P, Gual A. Treatment of alcohol use disorders in patients with alcoholic liver disease. J Hepatol. 2016;65 (3):618-630. doi:10.1016/j.jhep.2016.04.029

6. Gao B, Bataller R. Alcoholic liver disease: pathogenesis and new therapeutic targets. Gastroenterology. 2011;141(5):1572-1585. doi:10.1053/j.gastro.2011.09.002

7. Gupta P, Srivastav S, Saha S, Das PK, Ukil A. Leishmania donovani inhibits macrophage apoptosis and pro-inflammatory response through AKT-mediated regulation of $\beta$-catenin and FOXO-1. Cell Death Differ. 2016;23(11):1815-1826. doi:10.1038/cdd.2016.101
8. Zhao Y-Y, Zeng T, Xie K-Q, et al. Associations between the tumor necrosis factor-alpha gene and interleukin-10 gene polymorphisms and risk of alcoholic liver disease: a meta-analysis. Clin Res Hepatol Gas. 2016;40(4):428-439. doi:10.1016/j.clinre.2015.10.007

9. Kasztelan-Szczerbińska B, Surdacka A, Celiński K, et al. Prognostic significance of systemic inflammatory and immune balance in alcoholic liver disease with a focus on gender-related differences. PLoS One. 2015;10(6):e0128347. doi:10.1371/journal. pone. 0128347

10. Kawaratani H, Tsujimoto T, Douhara A, et al. The effect of inflammatory cytokines in alcoholic liver disease. Mediat Inflamm. 2013;2013:1-10. doi:10.1155/2013/495156

11. Xu T, Pan LX, Ge YX, et al. TMEM 88 mediates inflammatory cytokines secretion by regulating JNK/P38 and canonical Wnt/ $\beta$ catenin signaling pathway in LX-2 cells. Inflammopharmacology. 2018;26(5):1339-1348. doi:10.1007/s10787-017-0419-z

12. Schafer C, Parlesak A, Schütt C, et al. Concentrations of lipopolysaccharide-binding protein, bactericidal/permeability-increasing protein, soluble CD14 and plasma lipids in relation to endotoxaemia in patients with alcoholic liver disease. Alcohol Alcohol. 2002;37:81-86. doi:10.1093/alcalc/37.1.81

13. Petrasek J, Csak T, Szabo G. Toll-like receptors in liver disease. $A d v$ Clin Chem. 2013;59:155-201. doi:10.1016/b978-0-12-4052116.00006-1

14. Bessone F, Razori MV, Roma MG. Molecular pathways of nonalcoholic fatty liver disease development and progression. Cell Mol Life Sci. 2019;76:99-128.

15. Machado MV, Diehl AM. Pathogenesis of nonalcoholic steatohepatitis. Gastroenterology. 2016;150(8):1769-1777. doi:10.1053/j.gastro.2016.02.066

16. Hua F, Wang J, Ishrat $\mathrm{T}$, et al. Genomic profile of Toll-like receptor pathways in traumatically brain-injured mice: effect of exogenous progesterone. J Neuroinflamm. 2011;8(1):42. doi:10.1186/1742-20948-42

17. Ju M, Liu B, He Het al. MicroRNA-27a alleviates LPS-induced acute lung injury in mice via inhibiting inflammation and apoptosis through modulating TLR4/MyD88/NF-кB pathway. Cell Cycle. 2018;17:2001-2018.

18. Neo SY, Yang Y, Record J, et al. CD73 immune checkpoint defines regulatory NK cells within the tumor microenvironment. J Clin Invest. 2020;130(3):1185-1198. doi:10.1172/JCI128895

19. Ma XL, Shen MN, Hu B, et al. CD73 promotes hepatocellular carcinoma progression and metastasis via activating PI3K/AKT signaling by inducing Rap1-mediated membrane localization of P110 $\beta$ and predicts poor prognosis. J Hematol Oncol. 2019;12(1). doi:10.1186/s13045-019-0724-7

20. Stagg J, Beavis PA, Divisekera U, Liu MCP, Smyth MJ. CD73deficient mice are resistant to carcinogenesis. Cancer Res. 2012;72 (9):2190. doi:10.1158/0008-5472.CAN-12-0420

21. Yu J, Wang X, Lu Q, et al. Extracellular 5'-nucleotidase (CD73) promotes human breast cancer cells growth through AKT/GSK-3 $\beta$ / $\beta$-catenin/cyclinD1 signaling pathway. Int $J$ Cancer. 2018;142 (5):959-967. doi:10.1002/ijc.31112

22. Li H, Karmouty-Quintana H, Chen NY, Mills T, Davies J. Loss of CD73-mediated extracellular adenosine production exacerbates inflammation and abnormal alveolar development in newborn mice exposed to prolonged hyperoxia. Pediatr Res. 2017;82 (6):1039-1047. doi:10.1038/pr.2017.176

23. Caiazzo E, Cerqua I, Riemma MA, Turiello R, Cicala C. Exacerbation of allergic airway inflammation in mice lacking ECTO-5'-nucleotidase (CD73). Front Pharmacol. 2020;11. doi:10.3389/fphar.2020.589343

24. Bradaschia-Correa V, Josephson AM, Egol AJ, et al. Ecto-5'nucleotidase (CD73) regulates bone formation and remodeling during intramembranous bone repair in aged mice. Tissue Cell. 2017;49:545-551. 
25. Sun-sang JS, Li L, Huang L, et al. Proximal tubule CD73 is critical in renal ischemia-reperfusion injury protection. J Am Soc Nephrol. 2017;28:888-902. doi:10.1681/ASN.2016020229

26. Liu Z, Jia W, Jiang T, Dai J, Shuai C, Lv X. Regulation of CD39 expression in ATP-P2Y2R-mediated alcoholic liver steatosis and inflammation. Int Immunopharmacol. 2019;77:105915. doi:10.1016/ j.intimp.2019.105915

27. Hong Y, Yiping S, Shasha S, et al. Protective effects of dioscin against lipopolysaccharide-induced acute lung injury through inhibition of oxidative stress and inflammation. Front Pharmacol. 2017;8:120. doi:10.3389/fphar.2017.00120

28. Zhao G, Zhang $\mathrm{T}$, Ma X, et al. Oridonin attenuates the release of pro-inflammatory cytokines in lipopolysaccharide-induced RAW264.7 cells and acute lung injury. Oncotarget. 2017;8 (40):68153. doi:10.18632/oncotarget.19249

29. Xu MJ, Zhou Z, Parker R, Gao B. Targeting inflammation for the treatment of alcoholic liver disease. Pharmacol Ther. 2017;180:77. doi:10.1016/j.pharmthera.2017.06.007

30. Louvet A, Mathurin P. Alcoholic liver disease: mechanisms of injury and targeted treatment. Nat Rev Gastroenterol Hepatol. 2015;12 (4):231-242. doi:10.1038/nrgastro.2015.35

31. Luisa V, Mikhaïl A, Van H, et al. Targeting myeloid-derived cells: new frontiers in the treatment of non-alcoholic and alcoholic liver disease. Front Immunol. 2019;10:563.

32. Saha B, Momen-Heravi F, Furi Iet al. Extracellular vesicles from mice with alcoholic liver disease carry a distinct protein cargo and induce macrophage activation through heat shock protein 90 . Hepatology. 2018;67:1986-2000.

33. Singal AK, Shah VH. Therapeutic strategies for the treatment of alcoholic hepatitis. Semin Liver Dis. 2016;36(01):56-68. doi:10.1055/s-0036-1571297

34. Voican CS, Perlemuter G, Naveau S. Mechanisms of the inflammatory reaction implicated in alcoholic hepatitis: 2011 update. Clin Res Hepatol Gastroenterol. 2011;35(6):465-474. doi:10.1016/j. clinre.2011.01.017

35. Luo W, Xu Q, Wang Q, Wu H, Hua J. Effect of modulation of PPAR$\gamma$ activity on Kupffer cells M1/M2 polarization in the development of non-alcoholic fatty liver disease. Sci Rep. 2017;7(1):44612. doi: $10.1038 /$ srep44612

36. Shaughnessy LM, Swanson JA. The role of the activated macrophage in clearing Listeria monocytogenes infection. Front Biosci. 2007; 12:2683. doi:10.2741/2364

37. Jouanguy E, Döffinger R, Dupuis S, et al. IL-12 and IFN-gamma in host defense against mycobacteria and salmonella in mice and men. Curr Opin Immunol. 1999;11(3):346-351. doi:10.1016/S09527915(99)80055-7
38. Park J, Shao M, Kim MY, et al. An endoplasmic reticulum protein, Nogo-B, facilitates alcoholic liver disease through regulation of Kupffer cell polarization. Hepatology. 2017;65:1720-1734. doi:10.1002/hep. 29051

39. Pan G, Zhao Z, Tang C, et al. Soluble fibrinogen-like protein 2 ameliorates acute rejection of liver transplantation in rat via inducing Kupffer cells M2 polarization. Cancer Med. 2018;7(7):3168-3177. doi:10.1002/cam4.1528

40. Gual P, Pecker F, Bonnafous S, et al. M2 Kupffer cells promote M1 Kupffer cell apoptosis: a protective mechanism against alcoholic and nonalcoholic fatty liver disease. Hepatology. 2014;59:130-142. doi:10.1002/hep.26607

41. Mills JH, Thompson LF, Mueller C, et al. CD73 is required for efficient entry of lymphocytes into the central nervous system during experimental autoimmune encephalomyelitis. Proc Natl Acad Sci U S A. 2008;105(27):9325-9330. doi:10.1073/pnas.0711175105

42. Zhou S, Liu G, Guo J, Kong F, Chen S, Wang Z. Pro-inflammatory effect of downregulated CD73 expression in EAE astrocytes. Front Cell Neurosci. 2019;13. doi:10.3389/fncel.2019.00233

43. Zernecke A. CD73/Ecto-5'-nucleotidase protects against vascular inflammation and neointima formation. Circulation. 2006;113 (17):2120-2127. doi:10.1161/CIRCULATIONAHA.105.595249

44. Li LY, Yang CC, Li SW, Liu YM, Xu T. TMEM88 modulates the secretion of inflammatory factors by regulating YAP signaling pathway in alcoholic liver disease. Inflamm Res. 2020;69(8):789-800. doi:10.1007/s00011-020-01360-y

45. Zanin RF, Braganhol E, Bergamin LS, et al. Differential macrophage activation alters the expression profile of NTPDase and Ecto-5'Nucleotidase. PLoS One. 2012;7(2):e31205. doi:10.1371/journal. pone.0031205

46. Beninson LA, Fleshner M. Exosomes in fetal bovine serum dampen primary macrophage IL-1 beta response to lipopolysaccharide (LPS) challenge. Immunol Lett. 2015;163(2):187-192. doi:10.1016/j. imlet.2014.10.019

47. Chen SN, Tan Y, Xiao XC, et al. Deletion of TLR4 attenuates lipopolysaccharide-induced acute liver injury by inhibiting inflammation and apoptosis. Acta Pharmacol Sin. 2021;42(10):1610-1619. doi:10.1038/s41401-020-00597-x

48. Yin H, Huang L, Ouyang T, Chen L. Baicalein improves liver inflammation in diabetic $\mathrm{db} / \mathrm{db}$ mice by regulating HMGB1/TLR4/ NF- $\kappa \mathrm{B}$ signaling pathway. Int Immunopharmacol. 2018;55:55-62. doi:10.1016/j.intimp.2017.12.002
Journal of Inflammation Research

\section{Publish your work in this journal}

The Journal of Inflammation Research is an international, peerreviewed open-access journal that welcomes laboratory and clinical findings on the molecular basis, cell biology and pharmacology of inflammation including original research, reviews, symposium reports, hypothesis formation and commentaries on: acute/chronic inflammation; mediators of inflammation; cellular processes; molecular mechanisms; pharmacology and novel anti-inflammatory drugs; clinical conditions involving inflammation. The manuscript management system is completely online and includes a very quick and fair peerreview system. Visit http://www.dovepress.com/testimonials.php to read real quotes from published authors. 